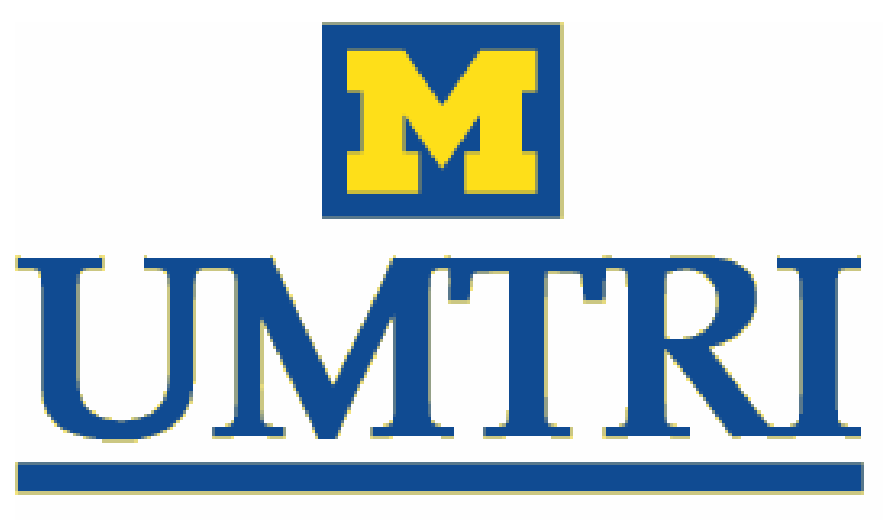

\title{
Use of Booster Seats by Michigan Children 4-8 Years of Age
}

\author{
David W. Eby \\ C. Raymond Bingham \\ Jonathon M. Vivoda \\ Trivellore Ragunathan
}

March 2005 


\title{
Use of Booster Seats by Michigan Children 4-8 Years of Age
}

\author{
David W. Eby \\ C. Raymond Bingham \\ Jonathon M. Vivoda \\ The University of Michigan \\ Transportation Research Institute
}

Trivellore Ragunathan

University of Michigan

Department of Biostatistics

Ann Arbor, MI 48109

U.S.A.

March 2005

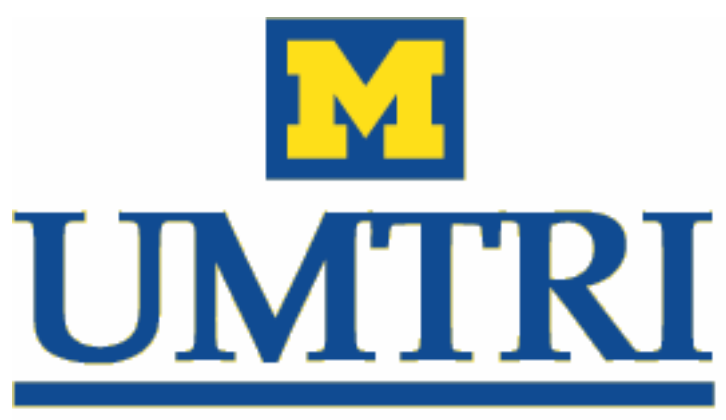


Technical Report Documentation Page

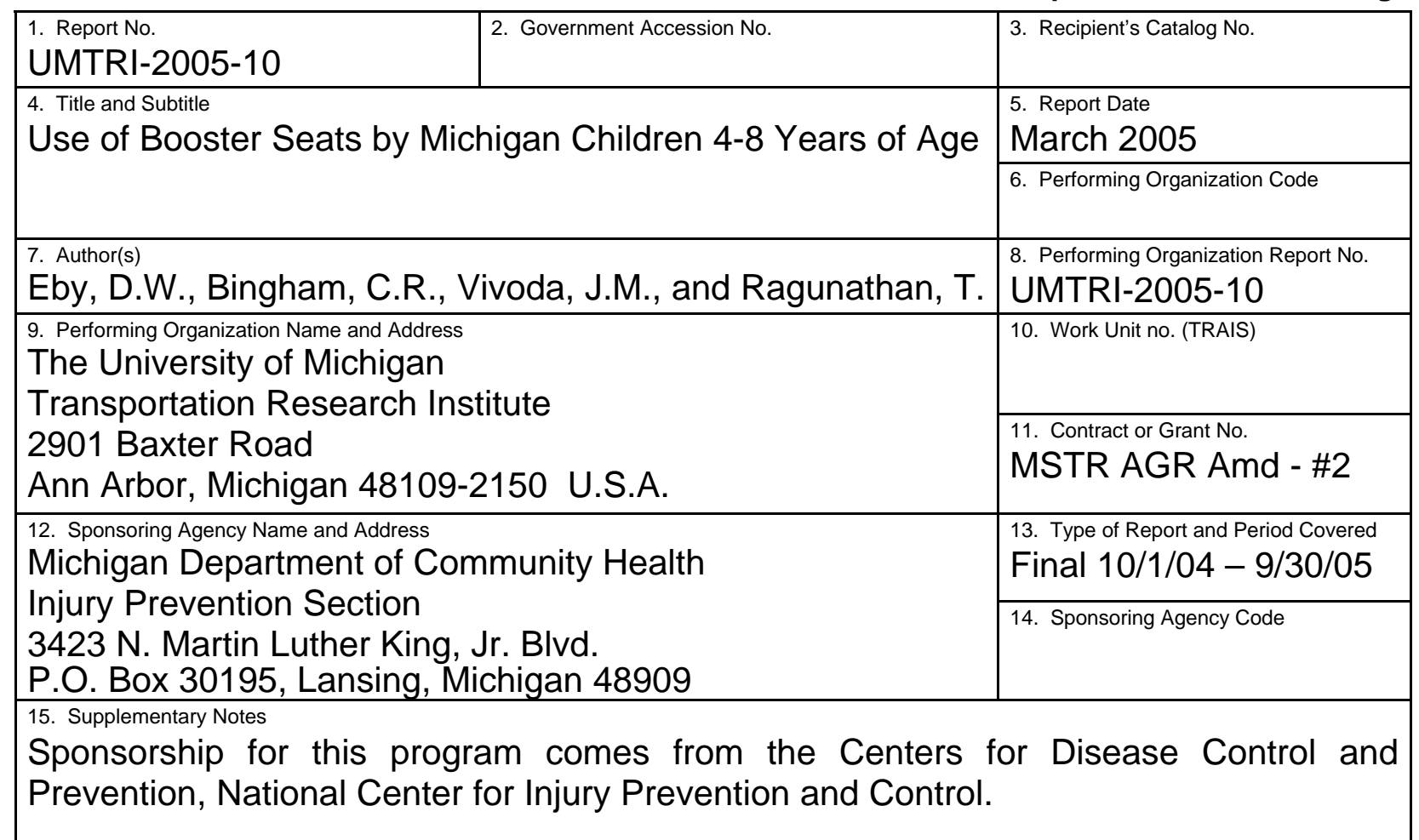

16. Abstract

This study reports the results of a statewide survey of restraint use by 4-8 year old children in Michigan conducted between July 13 and 29, 2004. In this study, 3,420 4-8 year old children were observed traveling in passenger cars, vans/minivans, sportutility vehicles, and pickup trucks. Restraint use was estimated for children traveling in all vehicles combined, as well as for each vehicle type separately. Children's restraint use was also calculated by the sex, age, and belt use of the driver. Separate estimates were also made of the restraint use of 4-8 year old children by the combination of sex and belt use of the driver. Overall, $8.6 \pm 5.9$ percent of 4-8 year old children were seated in a booster seat, $48.8 \pm 10.3$ percent were wearing a safety belt, $5.1 \pm 3.4$ percent were seated in a child safety seat, and the remaining $37.5 \pm 11.5$ percent were traveling completely unrestrained. When examining the rates by vehicle type, booster seat use was highest among children riding in sport-utility vehicles and lowest for those in pickup trucks. Surprisingly, children riding in passenger cars were more likely to be completely unrestrained than those in any other type of vehicle. While the sex of the driver did not seem to influence the restraint use of target-aged children, the driver's age did seem to have an effect. Booster seat use was quite low (0.6 percent) for children traveling with a driver over the age of 60 , compared to 7.0 and 9.1 percent for those riding with drivers 16-29 and 30-59 years of age, respectively. The safety belt use of the driver also had a substantial influence on children's restraint use. Irrespective of driver sex, children riding with belted drivers were traveling in booster seats about 10 percent of the time, while those riding with unbelted drivers were only in booster seats 1-2 percent of the time.

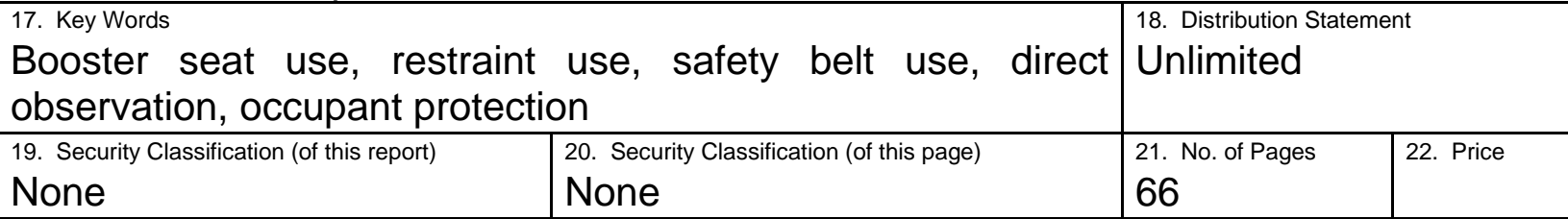


SI* (MODERN METRIC) CONVERSION FACTORS APPROXIMATE CONVERSIONS TO SI UNITS

\begin{tabular}{|c|c|c|c|c|}
\hline Symbol & When You Know & Multiply By & To Find & Symbol \\
\hline \multicolumn{5}{|c|}{ LENGTH } \\
\hline in & inches & 25.4 & millimeters & $\mathrm{mm}$ \\
\hline $\mathrm{ft}$ & feet & 0.305 & meters & $\mathrm{m}$ \\
\hline yd & yards & 0.914 & meters & $\mathrm{m}$ \\
\hline $\mathrm{mi}$ & miles & 1.61 & kilometers & $\mathrm{km}$ \\
\hline \multicolumn{5}{|c|}{ AREA } \\
\hline $\mathrm{in}^{2}$ & square inches & 645.2 & square millimeters & $\mathrm{mm}^{2}$ \\
\hline $\mathrm{ft}^{2}$ & square feet & 0.093 & square meters & $\mathrm{m}^{2}$ \\
\hline $\mathrm{yd}^{2}$ & square yard & 0.836 & square meters & $\mathrm{m}^{2}$ \\
\hline ac & acres & 0.405 & hectares & ha \\
\hline $\mathrm{mi}^{2}$ & square miles & 2.59 & square kilometers & $\mathrm{km}^{2}$ \\
\hline \multicolumn{5}{|c|}{ VOLUME } \\
\hline $\mathrm{fl} \mathrm{oz}$ & fluid ounces & 29.57 & milliliters & $\mathrm{mL}$ \\
\hline gal & gallons & 3.785 & liters & $\mathrm{L}$ \\
\hline $\mathrm{ft}^{3}$ & cubic feet & 0.028 & cubic meters & $\mathrm{m}^{3}$ \\
\hline $\mathrm{yd}^{3}$ & cubic yards & 0.765 & cubic meters & $\mathrm{m}^{3}$ \\
\hline \multicolumn{5}{|c|}{ NOTE: volumes greater than $1000 \mathrm{~L}$ shall be shown in $\mathrm{m}^{3}$} \\
\hline \multicolumn{5}{|c|}{ MASS } \\
\hline $\mathrm{OZ}$ & ounces & 28.35 & grams & $g$ \\
\hline lb & pounds & 0.454 & kilograms & $\mathrm{kg}$ \\
\hline $\mathrm{T}$ & short tons (2000 lb) & 0.907 & megagrams (or "metric ton") & Mg (or "t") \\
\hline \multicolumn{5}{|c|}{ TEMPERATURE (exact degrees) } \\
\hline${ }^{0} \mathrm{~F}$ & Fahrenheit & $\begin{array}{c}5(\mathrm{~F}-32) / 9 \\
\text { or }(\mathrm{F}-32) / 1\end{array}$ & Celsius & ${ }^{\circ} \mathrm{C}$ \\
\hline \multicolumn{5}{|c|}{ ILLUMINATION } \\
\hline fc & foot-candles & 10.76 & lux & Ix \\
\hline $\mathrm{fl}$ & foot-Lamberts & 3.426 & candela $/ \mathrm{m}^{2}$ & $\mathrm{~cd} / \mathrm{m}^{2}$ \\
\hline \multicolumn{5}{|c|}{ FORCE and PRESSURE or STRESS } \\
\hline & poundforce & 4.45 & newtons & $\mathrm{N}$ \\
\hline $\mathrm{lbf} / \mathrm{in}^{2}$ & poundforce per square inch & 6.89 & kilopascals & $\mathrm{kPa}$ \\
\hline \multicolumn{5}{|c|}{ APPROXIMATE CONVERSIONS FROM SI UNITS } \\
\hline Symbol & When You Know & Multiply By & To Find & Symbol \\
\hline \multicolumn{5}{|c|}{ LENGTH } \\
\hline $\mathrm{mm}$ & millimeters & 0.039 & inches & in \\
\hline $\mathrm{m}$ & meters & 3.28 & feet & $\mathrm{ft}$ \\
\hline $\mathrm{m}$ & meters & 1.09 & yards & yd \\
\hline $\mathrm{km}$ & kilometers & 0.621 & miles & mi \\
\hline \multicolumn{5}{|c|}{ AREA } \\
\hline $\mathrm{mm}^{2}$ & square millimeters & 0.0016 & square inches & in $^{2}$ \\
\hline & square meters & 10.764 & square feet & $\mathrm{ft}^{2}$ \\
\hline$m^{2}$ & square meters & 1.195 & square yards & $\mathrm{yd}^{2}$ \\
\hline ha & hectares & 2.47 & acres & $\mathrm{ac}$ \\
\hline $\mathrm{km}^{2}$ & square kilometers & 0.386 & square miles & $\mathrm{mi}^{2}$ \\
\hline \multicolumn{5}{|c|}{ VOLUME } \\
\hline $\mathrm{mL}$ & milliliters & 0.034 & fluid ounces & $\mathrm{fl} \mathrm{oz}$ \\
\hline L & liters & 0.264 & gallons & gal \\
\hline $\mathrm{m}^{3}$ & cubic meters & 35.314 & cubic feet & $\mathrm{ft}^{3}$ \\
\hline $\mathrm{m}^{3}$ & cubic meters & 1.307 & cubic yards & $\mathrm{yd}^{3}$ \\
\hline \multicolumn{5}{|c|}{ MASS } \\
\hline g & grams & 0.035 & ounces & $\mathrm{Oz}$ \\
\hline $\mathrm{kg}$ & kilograms & 2.202 & pounds & $\mathrm{lb}$ \\
\hline Mg (or "t") & megagrams (or "metric ton") & 1.103 & short tons (2000 lb) & $\mathrm{T}$ \\
\hline \multicolumn{5}{|c|}{ TEMPERATURE (exact degrees) } \\
\hline${ }^{\circ} \mathrm{C}$ & Celsius & $1.8 \mathrm{C}+32$ & Fahrenheit & ${ }^{\circ} \mathrm{F}$ \\
\hline \multicolumn{5}{|c|}{ ILLUMINATION } \\
\hline Ix & lux & 0.0929 & foot-candles & fc \\
\hline $\mathrm{cd} / \mathrm{m}^{2}$ & candela/mn $\mathrm{m}^{2}$ & 0.2919 & foot-Lamberts & $\mathrm{fl}$ \\
\hline \multicolumn{5}{|c|}{ FORCE and PRESSURE or STRESS } \\
\hline $\mathrm{N}$ & newtons & 0.225 & poundforce & lbf \\
\hline $\mathrm{kPa}$ & kilopascals & 0.145 & poundforce per square inch & $\mathrm{lbf} / \mathrm{in}^{2}$ \\
\hline
\end{tabular}

*SI is the symbol for the International System of Units. Appropriate rounding should be made to comply with Section 4 of ASTM E380. (Revised March 2003) 


\section{Acknowledgments}

This research was sponsored by the Michigan Department of Community Health $(\mathrm{MDCH})$ through a cooperative agreement with the Centers for Disease Control and Prevention (CDC), National Center for Injury Prevention and Control (NCIPC). We express our appreciation to several individuals who were essential for the completion of this project. Heather Hockanson and Linda Scarpetta from the $\mathrm{MDCH}$, Dr. Arlene Greenspan from the CDC NCIPC, and the Michigan Child Passenger Safety Coalition provided feedback on the study design. Field observation were conducted by Anna Cavnar, Christa Harrison, John Henion, Richard Messick, William Peters, Robin Potter, Russell Prince, and Renée St. Louis. Renée St. Louis also provided feedback on the report. Mary Chico and Judy Settles coordinated the contract and administrated procedures for the data collection .

David W. Eby, Ph.D.

C. Raymond Bingham, Ph.D.

Jonathon M. Vivoda, B.A.

Trivellore Ragunathan, Ph.D.

March 2005 


\section{Introduction}

The tragic outcome of motor vehicle crashes on child occupants is well known. Motor vehicle crashes are the leading cause of death for children 4-8 years of age (Subramanian, 2005), despite the fact that motor-vehicle-related fatalities in this age group have declined in recent years (National Highway Traffic Safety Administration, NHTSA, 2003). Nonuse of occupant restraints is an important factor in crash related child injuries and fatalities. Unrestrained children are more likely than children who are restrained to be injured, suffer more severe injuries, and die in motor vehicle crashes. In 2003, more than 50 percent of children killed in motor vehicle crashes were completely unrestrained (NHTSA, 2005a). Misuse of restraints is also a factor that increases the chances of severe injury or death for children. Studies have shown that 50 to 80 percent of 4-8 year old children, who should be placed in a booster seat, were inappropriately restrained in safety belts (Durbin et al., 2003; Eby et al., 2000). When compared to children using booster seats, 4-8 year old children using safety belts are 3.5 times more likely to suffer a significant injury, and 4.2 times more likely to suffer a significant head injury from a motor vehicle crash (Winston, et al., 2000).

Safety belts in both the front and back seat were designed to fit adults. Because of the small stature of children, safety belts do not fit them properly and the belts themselves can contribute to an increased risk of injury to children involved in motor vehicle crashes. The pattern of injuries to the abdomen and spine of children placed in safety belts is so characteristic that it has been named "safety belt syndrome." In order to compensate for children's small sizes, booster seats were designed to raise the child up so that both the lap and shoulder straps of adult safety belts fit children's bodies, especially the hips, chest, and neck. For the unboosted child, safety belts tend to ride up over the pelvis and against their soft abdomen, where the force of a crash can cause severe internal abdominal injuries. Additionally, many children ages 4-8 are not tall enough for the shoulder strap to lay over the chest and collarbone, and may either place the shoulder strap under their arm, which could fracture ribs, or behind their backs. This allows their upper bodies to move too far forward in a crash, putting them at risk for severe head trauma and spinal cord injury. If the shoulder strap of the safety belt is left 
in place across the body of the child, it tends to cross their neck, and contributes to neck injuries in a crash.

Because of the clear safety benefits of booster seat use in the 4-8 year old age group, NHTSA (2005b) recommends that once children outgrow their toddler safety seats, they be placed in booster seats until the safety belt fits them properly. Children are large enough for a lap and shoulder belt when they can sit against the vehicle seat back cushion with their knees bent over the bottom cushion (NHTSA recommends 4'9" tall, 80 pounds, and 8 years old). Despite NHTSA's recommendation, use of booster seats by 4-8 year old children has been found to be quite low. The Partners for Child Passenger Safety evaluated crash records from State Farm Insurance between 1998 and 2000 and found 4 to 13 percent booster seat use (Durbin, et al., 2003). Direct observation studies have also found low booster seat use rates for 4-8 year olds: using a convenience sample of vehicle occupants arriving at child safety seat clinics, Taft, Mickalide, and Taft (1999) found 37 percent use of booster seats; Ramsey et al. (2000) reported about 27 percent use at a sample of day care centers in the greater Seattle area; Decina and Knoebel (1996) found only 6 percent use of booster seats in a four-state convenience sample; and Ebel et al. (2003a, 2003b) found about 21 percent use at sites in the Northwest United States.

While these direct observation studies show interesting results, none have focused on statewide booster seat use. The purpose of the present study was to determine a statewide booster seat use rate, as well as trends in use, for the state of Michigan. Michigan is unique in that it has greater than 90 percent use of frontoutboard safety belts (Eby \& Vivoda, 2004), greater than 85 percent use of child safety seats for children under 4 (Eby, Kostyniuk, Miller, \& Vivoda, 2001; Eby, Kostyniuk, \& Vivoda, 1999), but low use of any kind of restraint for child passengers 4-15 years of age (Eby, Kostyniuk, \& Vivoda, 2001). In addition, Michigan does not legislate use of booster seats. Collectively, these findings suggest that booster seat use may be low in Michigan, despite the fact that the state has one of the highest safety belt use rates in the nation. 


\section{Methods}

Sample Design

The goal of this sample design was to select observation sites that represent accurately locations visited by Michigan children 4-8 years of age (target age). An ideal sample minimizes total survey error while providing sites that can be surveyed efficiently and economically; in this case, sites that have a high likelihood of target age children present. To achieve this goal, the following sampling procedure was used.

Michigan consists of 83 counties, many of which are sparsely populated. To reduce the costs associated with data collection at remote sites, NHTSA $(1992,1998)$ safety belt survey guidelines allow states to omit from their sample space the lowest population counties, provided these counties account for 15 percent or less of the state's total population. These guidelines were adopted for the present survey of booster seat use. Therefore, all 83 Michigan counties were rank ordered by population and the lowest population counties were eliminated from the sample space. This step reduced the sample space to the same 31 counties used in the most recent direct observation surveys of statewide safety belt use (see, e.g., Eby \& Vivoda, 2004).

Because we intended to compare booster seat use rates with statewide safety belt and child safety seat (CSS) use rates, the same statewide stratification procedure developed for the direct observation of safety belt use study and the CSS use study in Michigan (see Eby \& Kostyniuk, 1999; Vivoda \& Eby, 2003), was used in the present survey of statewide booster seat use. The 31 counties were organized into four strata. The strata were constructed by obtaining historical belt use rates and vehicle miles of travel (VMT) for each county. Because of its disproportionately high VMT, high concentration of people, and to ensure that observation sites are selected within Wayne County, this county was a separate stratum. The three other strata were constructed by rank-ordering each county by historical belt use rates and then adjusting the stratum boundaries until there were roughly equal total VMT within each stratum. 
The number of observation sites for the survey (176) was determined based on within- and between-county variances from previous adult belt use surveys and an estimated 20 target age children per observation period for the current survey based upon pilot testing. Adult belt use rates were used for this estimation procedure because they were likely to correlate highly with booster seat use by children under 10 years of age. In previous work we have found that adult safety belt use and CSS use are positively correlated (Eby \& Kostyniuk, 1999).

Analyses were conducted to determine the types of sites to be used in the proposed survey. We analyzed National Household Travel Survey (NHTS) data to assess the locations where children aged 4-8 travel (Bureau of Transportation Statistics, 2005). When trip purposes that yielded locations that could not be sampled were removed (return home, serve passenger, other family/personal), there were four site types that were discovered from this analysis: recreation areas; shopping centers/grocery stores; restaurants; and schools. Because the study was to be conducted in summer, day care centers were substituted for school sites in this study. In addition, we have utilized recreation sites in previous work (Eby, Kostyniuk, \& Vivoda, $1999,2001)$ and have found that these sites are difficult for data collection because they generally have a large number of entrances and exits and many sites have programs in which children tend to arrive in clusters or only during pre-scheduled events. Therefore, shopping centers/grocery store and restaurants were selected as the other types of sites for the present study. For these sites, it was important to select businesses that would have a high likelihood of target-age children. Recent data show that 90 percent of US children between the ages of 3 and 9 visit a McDonald's restaurant every month (Schlosser, 2001). Because McDonald's restaurants are located throughout Michigan, all restaurant sites were McDonald's restaurants.

Within each stratum, 44 observation sites were selected randomly from lists of potential sites. A list of all day care centers in Michigan was obtained from the Michigan Family Independence Agency (2004); the list of McDonald's restaurants was generously provided by the Michigan McDonald's headquarters; and the list of grocery 
stores/shopping centers was downloaded from SMARTPages.com, an Internet "yellow pages" site. Of the 44 sites per stratum, 11 were day care centers, 11 were McDonald's restaurants, and 22 were grocery stores/shopping centers. This distribution of sites was based upon scheduling considerations. Since day care centers could only be observed when children were being dropped off, and McDonald's restaurants needed to be observed during high traffic times (breakfast, lunch, or dinner times), fewer of these sites could be observed during a day of data collection. Grocery store/shopping center sites, on the other hand, could be observed during anytime of the day. Therefore, in order to have a complete day of data collection, generally only one day care center, one McDonald's, and two grocery store/shopping centers sites could be observed.

As just discussed, scheduling of sites was constrained by the need to observe day care sites in the morning, and McDonald's sites during meal times. Therefore, we could not randomize by time of day. In addition, day care sites could not be observed during the weekend. Within this constraint, the day of week for site observation was randomly selected using a clustering procedure. A cluster was made up of spatially adjacent sites that were observed during a single day. Clusters were randomly assigned to a day of week.

\section{Data Collection Procedures}

During data collection, trained field staff observed the restraint use and sex of 4-8 year old motor vehicle occupants traveling in passenger cars, vans/minivans, sportutility vehicles, and pickup trucks. Restraint use, sex, and age of the driver was also observed and recorded. Observations were conducted as vehicles entered the parking areas of businesses frequented by children of this age group.

\section{Data Collection Forms}

Data were collected during the survey using personal digital assistants (PDAs). An electronic form, the "booster seat use form," was developed for PDA data collection. For each site surveyed, separate electronic copies of the booster seat use form were created in advance. This form allowed observers to provide descriptive information 
including the site number, the date of observations, the start and end time of observations, and any comments about the site. The form also allowed observers to identify the restraint use, sex, and estimated age of each vehicle driver; the restraint use, sex, and seating location of all 4-8 year old vehicle occupants; as well as the vehicle type. For a more detailed description of the PDA data collection process, see Appendix A.

\section{Procedures at Each Site}

Observations were conducted at three types of sites in this study: day care centers, McDonald's restaurants, and shopping centers/grocery stores. In order to maximize the chances of observing target-age children visiting these sites throughout the day, an observation schedule was created that considered the busiest times for each of these types of businesses. As such, all day care centers were observed from 7:45 to 9:15 am. Day care center observations were conducted during drop-off times rather than pick-up times to eliminate potential biases. First, more opportunity to note the presence of the observers could have alerted parents to the study; and second, motor vehicle occupants sometimes buckle their safety belt after the vehicle is in motion. Since observations were only conducted during drop-off times, parents did not have as much opportunity to discover the nature of the study, and late safety belt bucklers were not an issue.

Observations at McDonalds and grocery store/shopping center sites were for one hour. Observers collected data only as vehicles entered the parking area. Overall, the scheduling format utilized for the three site types allowed for the best balance of efficiency between maximizing observations of target-age children and utilizing the time available given the constraints of the data collection time period.

During data collection, all observers traveled in teams of two. For most sites in the study, both observers in the team collected data at the same site. On some occasions, however, the teams split up and each observer collected data at different nearby sites. Splitting up the teams at certain sites was necessary in order to finish 
data collection at all sites within the given time period. Whether teams collected data at the same site or at different nearby sites was pre-determined by the project director prior to the beginning of data collection.

Upon arrival at a site, observer teams discussed the appropriate standing location for each person. At site locations where there were multiple entrances to the parking area, observers were instructed to stand near the roadway at different entrance locations. If there was only one entrance, observers stood together and communicated with one another about the vehicles from which each observer would collect data, being careful that both observers did not collect data from the same vehicle. If there were more than two entrances to the site's parking area, observers were instructed to choose the two entrances that appeared to be the busiest, thus increasing the chances of observing as many target-aged children as possible. When observer teams split up to collect data alone at different nearby sites, the same procedures were followed to select standing location.

At each site, observations began at the scheduled time for each site and continued until the end of the time period (one and a half hours at day care center sites and one hour for McDonald's and grocery store/shopping center site locations). Observers recorded data for as many eligible vehicles as they could observe. An eligible vehicle was defined as a passenger car, van/minivan, sport utility-vehicle, or pickup truck containing a target-aged child. Observers looked into every vehicle that entered the parking area to determine if a target-age child was present in any seating position. If a target-age child was present, the observer recorded the appropriate data about all target-age children in the vehicle, as well as the aforementioned driver information. If traffic flow was heavy, observers were instructed to look into each car that passed (if possible) for a target-aged child, then stop and record those data. Once the data were recorded, observers were to look up and continue checking for the next vehicle with target-age children. 


\section{Observer Training}

Prior to data collection, observers participated in 4 days of intensive training, including both classroom review of data collection procedures and practice field observations. Each observer received a training manual containing detailed information on field procedures for observations, PDA use, and administrative policies and procedures (the complete training manual can be found in Appendix B). A site schedule identifying the location, date, and time of observations for each site was included in the manual (see Appendix $C$ for a listing of the sites).

After intensive review of the manual and a training session about common types of child restraint devices, observers conducted practice observations at several site locations. Specific training locations were chosen where observers were likely to see the most target-aged children, and that would represent the types of sites and situations that would actually be encountered during data collection. None of the practice site locations were used as sites in the actual study. Training at practice sites focused on identifying vehicles containing target-age children, recording restraint use and sex of target-age children, using the PDA for data collection, determining where to stand at different site location types, and estimating and recording the safety belt use, sex, and age of the vehicle driver. Some of this training involved asking the driver the age of child passengers to increase the accuracy of the visual judgment of age. Formal validation of the visual assessment of ages was not conducted, since previous work has shown that this direct observation method is nearly 90 percent accurate (Moeller, Berger, Salvador, \& Helitzer (2002).

After an initial acclimation period, observers began to work in teams, observing the same vehicles but recording data independently on their own PDA. The data from each observer were then compared for accuracy to that of every other observer. Observer teams continued to work together throughout the training period until an interobserver reliability of at least 85 percent for all measures on drivers and target-age passengers was reached between all observers. However, one observer did not reach 
the 85 percent agreement rate with all other observers during the training period. This observer was given additional training but was not retested for inter-observer reliability.

Each observer was provided with an atlas of Michigan county maps and all necessary field supplies. Electronic mapping software was also provided for observers on the PDAs. Observers were given time to locate their assigned sites on the appropriate maps (or electronically) and plan travel routes to the sites. Field procedures were reviewed for the final time, and observers were informed that unannounced site visits would be made by the field supervisor during data collection to ensure adherence to study protocols.

\section{Observer Supervision and Monitoring}

During data collection, unannounced site checks were conducted by the field supervisor on at least two occasions for each observer. Contact between the field supervisor and field staff was also maintained on a regular basis through the following: telephone calls to report progress and discuss problems encountered in the field, emails to the field supervisor from observers' PDAs containing data from the preceding day, text messages to the observers' PDAs to alert them of any important information, and visits to the UMTRI office to deliver expense forms and timesheets. Field staff were instructed to call the field supervisor's home or cellular phone if problems arose during evening hours or on weekends.

Incoming data files were examined by the field supervisor and problems (e.g., missing data or discrepancies between the booster seat use form and observer schedule) were noted and discussed with field staff. Comments on the booster seat use form about site-specific characteristics that might affect future surveys (e.g., traffic flow patterns, site access, business hours of operation) were noted.

\section{Estimation of Booster Seat Use Rates}

Rates of booster seat use were estimated, along with variances and confidence intervals, for the state of Michigan using data collected at locations commonly visited by 
4-8 year olds riding in motor vehicles. Past research of the type reported here has typically ignored noise-variance arising from varying diurnal rates of travel to the types of sites sampled, and error resulting from non-independence of observations of passengers riding in the same vehicle. This research attempted to reduce error resulting from these sources of systematic extraneous variance using three methods. First, non-independence of booster seat use by target-age children riding in the same vehicle was addressed by grouping vehicles with the same number of target-age occupants into separate clusters. Three clusters were defined, including one, two, and three or more target-age occupant clusters. Numbers of cars with more than three target-age occupants were rare and could not be analyzed separately.

Second, the car clusters were grouped based on the type of site and the time-ofday when the observations took place. Seven observation time/site type clusters resulted: daycare centers (7:45 am to 9:15 am); McDonald's restaurants in the morning (8:30 am to $11: 00 \mathrm{am})$, at noon (11:15 am to $1: 30 \mathrm{pm})$, and in the afternoon (2:00 pm to 5:30 pm); and grocery stores/shopping centers in the morning (9:00 am to 11:15 am), early afternoon (1:30 pm to $3: 45 \mathrm{pm})$, and late afternoon (3:00 pm to 6:45 pm). By grouping the data in this manner, error resulting from differing rates of booster seat use across the three types of sites was taken into account.

Finally, the variance in rates of travel across the sites and times of day was taken into account by adjusting the analyses for varying population rates of travel to the types of sites and times of day when the observations were made. Weights were calculated using data from the NHTS (Bureau of Transportation Statistics, 2005) to measure the proportion of the total population of households with target-aged children that reported traveling to daycare, eat, and shop during the times of day when observations were made. These weights were then used to adjust the analyses to account for diurnal variation in travel to the types of locations that were observed. NHTS data selected and weighted to represent travel patterns in the Northeastern Midwest region of the United States were used to estimate adjustment weights for this study. 
Rates were initially calculated separately for car clusters within stratum and time/location cluster, and were then combined and weighted up, first to the site level, then to the stratum, and finally to represent the state of Michigan.

The observational data were post-stratified and weighted to represent the target population of drivers. The post-strata were defined by the combination of four regions of Michigan, and seven site and time combination (i.e., Shopping: morning, noon, afternoon; Food: McDonald, Morning, Noon and Afternoon; and Day Care drop-off) and the gender of the driver. Not all of 56 combinations were possible in the data set (i.e., observations at certain sites and times were not carried out in some locations). The unobserved combinations were minimally collapsed across other categories (e.g., stratum, site-time). The population size and number of households with age-eligible children were also estimated for each stratum using US Census Data, letting $n_{h}, h=1,2, \ldots, H$ be the sample sizes and $N_{h}$ the estimated population sizes in the strata.

Next, we used the NHTS database to estimate the proportion of male (female) drivers who gave reasons for driving as: drop-off children in the daycare, shopping (morning, noon and afternoon) and to eat (morning, noon and afternoon). The proportions were weighted to account for the complex survey design, nonresponse and post-stratification of the NHTS. These proportions were calculated using data from the North central Region of the US to represent the entire state of Michigan and it was assumed that these proportions were represented the subregions used in our analysis. Letting $W_{h}, h=1,2, \ldots, H$ denote the proportions for the $H$ strata. The post-stratification weight was defined as,

$$
w_{i h}=\frac{W_{h} N_{h}}{n_{h}}
$$

where $i=1,2, \ldots, h$ and $h=1,2, \ldots, H$. To further account for differential selection of the number of sites across strata, we adjusted the weight by multiplying it by the ratio, $K_{h} / k_{h}$, of total number of possible sites to the actual number of sites sampled in 
stratum $h$. The analyses were performed using the Survey Means Procedure in SAS 9.1 to incorporate the weights, and account for the post-stratification and clustering. 


\section{Results}

Table 1 shows the restraint use of Michigan children aged 4-8 years of age overall and by type of vehicle in which they were traveling. As shown in this table, use of booster seats by target aged children was only about 9 percent statewide, with another 49 percent incorrectly using a safety belt. The " \pm " value following the use rate indicates a 95 percent confidence band around the percentage. This value should be interpreted to mean that we are 95 percent sure that the actual Michigan booster seat use rate falls somewhere between $2.8 \%$ and $14.4 \%$ and the unrestrained use rate falls somewhere between $26.0 \%$ and $49.9 \%$. A surprising 38 percent of $4-8$ year olds in Michigan were completely unrestrained. Analysis by the type of vehicle showed that booster seat use was highest for target-aged children traveling in SUVS and lowest for those traveling in pickup trucks. The highest rate of completely unrestrained children (44 percent) was found traveling in passenger vehicles.

Table 2 shows the restraint use of Michigan children 4-8 years of age by the sex and age of the driver. The study found that twice as many females as males were transporting target-age children. No differences were found between the driver sexes for target-age child restraint use. Restraint use of children varied widely by the age of the driver. For drivers 16-29 years of age, booster seat use was 7 percent while more than 50 percent of target-age children were completely unrestrained. Drivers in the middle age group used booster seats for target-age children 9 percent of the time and had about 34 percent of children completed unrestrained. Children traveling with drivers 60 years of age or older had the lowest use of booster seats (less than 1 percent), as well as the lowest percentage of riding completely unrestrained (21 percent).

Table 3 shows restraint use of 4-8 year old children in Michigan by the safety belt use of the vehicle driver with whom they were traveling and by driver sex. As can be seen, booster seat use was much higher when the driver was using a safety belt. In addition, target-child safety belt use was significantly higher when the driver was belted. For unbelted drivers, more than 90 percent of the target-aged children were riding 
completely unrestrained. Analysis of child restraint use by driver belt use and sex showed that the effect of driver belt use on 4-8 year old restraint use did not vary by driver sex.

\begin{tabular}{|lc|}
\hline \multicolumn{2}{|c|}{ Table 1: 4-8 Year Old Restraint Use in Michigan by } \\
Vehicle Type.
\end{tabular}




\begin{tabular}{|c|c|c|}
\hline \multicolumn{3}{|c|}{$\begin{array}{c}\text { Table 2: 4-8 Year Old Restraint Use in Michigan bj } \\
\text { Driver Sex and Age. }\end{array}$} \\
\hline Variable & $\mathrm{N}$ & Percent Use \\
\hline Female Driver & 2251 & \\
\hline Booster Seat & & $8.6 \pm 5.9$ \\
\hline Belted & & $48.8 \pm 10.3$ \\
\hline Child Safety Seat & & $5.1 \pm 3.4$ \\
\hline Unrestrained & & $37.5 \pm 11.4$ \\
\hline Male Driver & 1169 & \\
\hline Booster Seat & & $8.8 \pm 3.1$ \\
\hline Belted & & $53.0 \pm 6.8$ \\
\hline Child Safety Seat & & $3.0 \pm 1.1$ \\
\hline Unrestrained & & $35.2 \pm 6.8$ \\
\hline Driver Age 16-29 & 783 & \\
\hline Booster Seat & & $7.0 \pm 4.4$ \\
\hline Belted & & $38.6 \pm 6.4$ \\
\hline Child Safety Seat & & $3.0 \pm 2.2$ \\
\hline Unrestrained & & $51.4 \pm 10.1$ \\
\hline Driver Age $30-59$ & 2548 & \\
\hline Booster Seat & & $9.1 \pm 7.4$ \\
\hline Belted & & $51.0 \pm 13.5$ \\
\hline Child Safety Seat & & $5.7 \pm 4.2$ \\
\hline Unrestrained & & $34.1 \pm 14.9$ \\
\hline Driver Age 60+ & 85 & \\
\hline Booster Seat & & $0.6 \pm 2.0$ \\
\hline Belted & & $73.9 \pm 9.6$ \\
\hline Child Safety Seat & & $4.3 \pm 10.0$ \\
\hline Unrestrained & & $21.2 \pm 8.0$ \\
\hline
\end{tabular}




\begin{tabular}{|c|c|c|}
\hline \multicolumn{3}{|c|}{$\begin{array}{c}\text { Table 3: 4-8 Year Old Restraint Use in Michigan bj } \\
\text { Driver Safety Belt Use and Sex. }\end{array}$} \\
\hline Variable & $\mathbf{N}$ & Percent Use \\
\hline Unbelted Driver & 329 & \\
\hline Booster Seat & & $1.9 \pm 2.7$ \\
\hline Belted & & $6.4 \pm 7.9$ \\
\hline Child Safety Seat & & $1.1 \pm 2.5$ \\
\hline Unrestrained & & $90.6 \pm 12.2$ \\
\hline Belted Driver & 3082 & \\
\hline Booster Seat & & $10.0 \pm 7.1$ \\
\hline Belted & & $57.7 \pm 6.0$ \\
\hline Child Safety Seat & & $6.0 \pm 4.0$ \\
\hline Unrestrained & & $26.4 \pm 5.0$ \\
\hline Unbelted Female Driver & 185 & \\
\hline Booster Seat & & $1.9 \pm 2.7$ \\
\hline Belted & & $6.3 \pm 7.9$ \\
\hline Child Safety Seat & & $1.1 \pm 2.5$ \\
\hline Unrestrained & & $90.7 \pm 12.3$ \\
\hline Belted Female Driver & 2061 & \\
\hline Booster Seat & & $9.9 \pm 7.1$ \\
\hline Belted & & $57.7 \pm 5.6$ \\
\hline Child Safety Seat & & $6.0 \pm 4.1$ \\
\hline Unrestrained & & $26.4 \pm 4.2$ \\
\hline Unbelted Male Driver & 144 & \\
\hline Booster Seat & & $1.3 \pm 0.4$ \\
\hline Belted & & $19.8 \pm 10.0$ \\
\hline Child Safety Seat & & $0.2 \pm 0.1$ \\
\hline Unrestrained & & $78.7 \pm 10.4$ \\
\hline Belted Male Driver & 1021 & \\
\hline Booster Seat & & $10.0 \pm 3.7$ \\
\hline Belted & & $57.6 \pm 7.7$ \\
\hline Child Safety Seat & & $3.4 \pm 1.3$ \\
\hline Unrestrained & & $29.0 \pm 7.7$ \\
\hline
\end{tabular}




\section{Discussion}

The purpose of this study was to determine the patterns of restraint use for 4-8 year old children across the state of Michigan. Of particular interest was the rate of booster seat use. The study found that overall use of booster seats by target-aged children was slightly less than 9 percent. This rate is similar to that found by Durbin et al., (2003) through crash record analysis, but lower than found in previous direct observation studies in other parts of the US (Ramsey et al., 2000; Decina \& Knoebel, 1996; Ebel, 2003a, 2003b). One possible reason for this difference in use is the fact that the present study is the first to measure booster seat use over an entire state.

The results showed that about one-half of target-age children were inappropriately restrained in safety belts. As discussed previously, the safety belt provides less protection, and may even cause injury, to target-age children during a motor-vehicle crash (Winston, et al., 2000). In addition, about one-third of 4-8-year old children in Michigan were traveling in vehicles completely unrestrained. Given that restraint use for other age groups in Michigan is significantly higher than found for 4-8 year olds (see e.g., Eby \& Kostyniuk, 1999; Eby \& Vivoda, 2004), the low restraint use discovered here may indicate that drivers allow children to ride unrestrained because the safety belt does not fit properly. Collectively, these findings indicate that the vast majority of Michigan children are at greater risk of death and injury from an automobile crash than if they were properly restrained in booster seats.

Use of booster seats was influenced by the type of vehicle in which the targetaged child was traveling, with booster seat use highest for SUVs and lowest for pickup trucks. The low use for pickup trucks follows similar patterns for safety belt use in pickup trucks found previously in Michigan (see e.g., Eby, Molnar, \& Olk, 2000; Eby, Fordyce, \& Vivoda, 2002; Eby \& Vivoda, 2004; Eby, Vivoda, \& Fordyce, 2002). Surprisingly, the highest rate of nonuse of any restraint was found in passenger vehicles, the most common vehicle on Michigan roadways. Without further research, we cannot provide an explanation for why this occurs. 
Study results showed that restraint use for target-aged children in Michigan was not influenced by the sex of the driver but varied greatly by the driver's age. Booster seat use was quite low for drivers over 60 years of age when compared to younger drivers. Similar results have been found for the use of child safety seats in Michigan (Eby \& Kostyniuk, 1999). This finding suggests that grandparents or older relatives of the target-age children in Michigan may not have access to, or know how to use booster seats. This conclusion is further bolstered by the fact that restraint use of any type for target-age children was quite low when traveling with the oldest drivers.

The study showed that booster seat use of target-aged children was significantly influenced by whether or not the driver was using a safety belt, a finding similar to that found for child safety seat use in Michigan (Eby \& Kostyniuk, 1999) and nationally (Glassbrenner, 2005). This effect was the same regardless of the driver's sex. Thus, stricter enforcement of the adult safety belt use law in Michigan might have the added benefit of increasing restraint use for the 4-8 year old children traveling in automobiles.

In conclusion, these results show that Michigan has great strides to make in ensuring the safety of its 4-8 year old residents. Given the success Michigan has had in increasing adult safety belt in the last decade (Eby, Molnar, \& Olk, 2000; Eby \& Vivoda, 2004; Eby, Vivoda, \& Fordyce, 2002), efforts to increase the use of booster seats in this state have a good chance of success. It might be beneficial for traffic safety professionals to model efforts to increase booster seat use on the approach that worked in Michigan for increasing adult safety belt use. Michigan began by passing legislation that required use of a safety belt, followed by strong enforcement campaigns with appropriate advertising and community-based programs to increase safety belt use in hard-to-reach populations. Thus, the first step for enhancing safety in Michigan's 4-8 year old population is the passage of legislation mandating booster seat use for appropriately aged/sized children. This vital first step must them be followed up with intensive public education and enforcement campaigns. 


\section{References}

Bureau of Transportation Statistics (2005). National Household Transportation Survey. URL: http://www.bts.gov/programs/national household travel survey/. Accessed: February, 2005.

Decina, L.E. \& Knoebel, K.Y. (1996). Patterns of Misuse of Child Safety Seats. (Report No. DOT-HS-808-440). Washington, DC: United States Department of Transportation.

Durbin D.R., Elliott M.R., \& Winston F.K. (2003). Belt-Positioning Booster Seats and Reduction of Injury Among Children in Vehicle Crashes. Journal of American Medical Association, 289, 2835-2840.

Ebel, B.E., Koepsell, T.D., Bennett, E.E., \& Rivara, F.P. (2003a). Use of booster seats in motor vehicles following a community campaign: A controlled trial. Journal of the American Medical Association, 289, 879-884.

Ebel, B.E., Koepsell, T.D., Bennett E.E., \& Rivara, F.P. (2003b). Too small for a seatbelt: Predictors of booster seat use by child passengers. Pediatrics, 111, 323-327.

Eby, D.W., Fordyce, T.A., \& Vivoda, J.A. (2002). A comparison of safety belt use in commercial and noncommercial vehicles. Accident Analysis \& Prevention, 34, 285-291.

Eby, D.W. \& Kostyniuk, L.P. (1999). A statewide analysis of child safety seat use and misuse in Michigan. Accident Analysis \& Prevention, 31, 555-566.

Eby, D.W., Kostyniuk, L.P., Miller, L.L., \& Vivoda, J.M. (2001). Child Safety Seat Use in Michigan. (Report No. UMTRI-2001-26). Ann Arbor, MI: University of Michigan Transportation Research Institute.

Eby, D.W., Kostyniuk, L.P., \& Vivoda, J.M. (1999). An Analysis of Restraint Use by Children in Michigan. (Report No. UMTRI-99-24). Ann Arbor, MI: University of Michigan Transportation Research Institute.

Eby, D.W., Kostyniuk, L.P., \& Vivoda, J.M. (2001). Restraint use patterns for older child passengers in Michigan. Accident Analysis \& Prevention, 33, 235-242.

Eby, D.W., Kostyniuk, L.P., Vivoda, J.M., \& Fordyce, T.A. (2000). Patterns of Child Restraint Use in Michigan. (Report No. UMTRI-2000-30). Ann Arbor, Ml: University of Michigan Transportation Research Institute.

Eby, D.W., Molnar, L.J., \& Olk, M.L. (2000). Trends in driver and front-right passenger safety belt use in Michigan: 1984 to 1998. Accident Analysis \& Prevention, 32 , 837-843. 
Eby, D.W. \& Vivoda, J.M. (2004). A Study of Safety Belt Use Surrounding the May Mobilization, 2004. (Report No. UMTRI-2004-24). Ann Arbor, Ml: University of Michigan Transportation Research Institute.

Eby, D.W., Vivoda, J.M., \& Fordyce, T.A. (2002). The effects of standard enforcement on Michigan safety belt use. Accident Analysis \& Prevention, 34, 815-825.

Glassbrenner, D. (2005). Child Restraint Use in 2004 - Overall Results. (Report No. DOT-HS-809-845). Washington, DC: US Department of Transportation.

Michigan Family Independence Agency (2004). Statewide Search for Child Day Care Centers and Homes URL: www.cis.state.mi.us/brs cdc/sr Ifl.asp). Accessed January, 2004.

Moeller, S., Berger, L., Salvador, J.G., \& Helitzer, D. (2002). How old is that child? Validating the accuracy of age assignments in observational surveys of vehicle restraint use. Injury Prevention, 8, 248-251.

National Highway Traffic Safety Administration (1992). Guidelines for State Observational Surveys of Safety Belt and Motorcycle Helmet Use. Federal Register, 57(125), 28899-28904.

National Highway Traffic Safety Administration (1998). Uniform Criteria for State Observational Surveys of Seat Belt Use. (Docket No. NHTSA-98-4280). Washington, DC: US Department of Transportation. Washington, DC: US Department of Transportation

National Highway Traffic Safety Administration (2003). Traffic Safety Facts: Children. (Report No. DOT-HS-809-762). Washington, DC: US Department of Transportation.

National Highway Traffic Safety Administration (2005a). Traffic Safety Facts: 2003. (Report No. DOT-HS-809-775). Washington, DC: US Department of Transportation.

National Highway Traffic Safety Administration (2005b). General Child Passenger Safety Seat Use Information. URL: www.nhtsa.dot.gov/people/injury/childps. Accessed: March 2005.

Ramsey, A., Simpson, E., \& Rivara, F.P. (2000). Booster seat use and reasons for nonuse. Pediatrics, 106, E20.

Schlosser, E. (2001). Fast Food Nation. New York, NY: Houghton Mifflin.

Subramanian, R. (2005a). Motor Vehicle Traffic Crashes as a leading Cause of Death in the United States, 2002. (Report No. DOT-HS-809-831). Washington, DC: US Department of Transportation. 
Taft, C.H., Mickalide, A.D.,\& Taft, A.R. (1999). Child Passengers at Risk in America: A National Study of Car Seat Misuse. Washington, DC: National Safe Kids Campaign.

Vivoda, J.M. \& Eby, D.W. (2003). Direct Observation of Safety Belt Use in Michigan: December 2002. Report No. UMTRI-2003-04. Ann Arbor, MI: University of Michigan Transportation Research Institute.

Vivoda, J.M. \& Eby, D.W. (in press). Using personal digital assistants (PDAs) for the collection of safety belt use data in the field. Behavior Research Methods Instruments and Computers.

Winston, F.K., Durbin, D.R., Kallan, M.J., \& Moll, E.K. (2000). The danger of premature graduation to seat belt for young children. Pediatrics, 105, 1179-1183. 


\section{APPENDIX A}

Personal Digital Assistant Instructions 
During the current study, all data collection was conducted using Personal Digital Assistants (PDAs). The use of PDAs for data collection is superior to paper and pencil method for several reasons. PDAs decrease the time usually necessary for transformation of paper data into an electronic format, data collection is equally accurate and fast, and PDAs are easier to use in inclement weather (see Vivoda \& Eby, in press, for a comparison of the PDA and paper data collection methods). As previously described, prior to the beginning of data collection, an electronic form called the booster seat use form was developed. The following pages show examples of this form and discuss other factors related to using PDAs for restraint use data collection.

Observers began data collection for each site by opening the proper electronic file within HanDBase ${ }^{\mathrm{TM}}$ (the database program used to create the booster seat use form). These files were named to correspond with the site number and day of data collection. Once the proper file was open, observers tapped on the "start info" button and then entered the three-digit site number, the date of observation, and the start time for the site (see Figure 1). For entry of observation date and time, the PDA's calendar function was incorporated into the form.
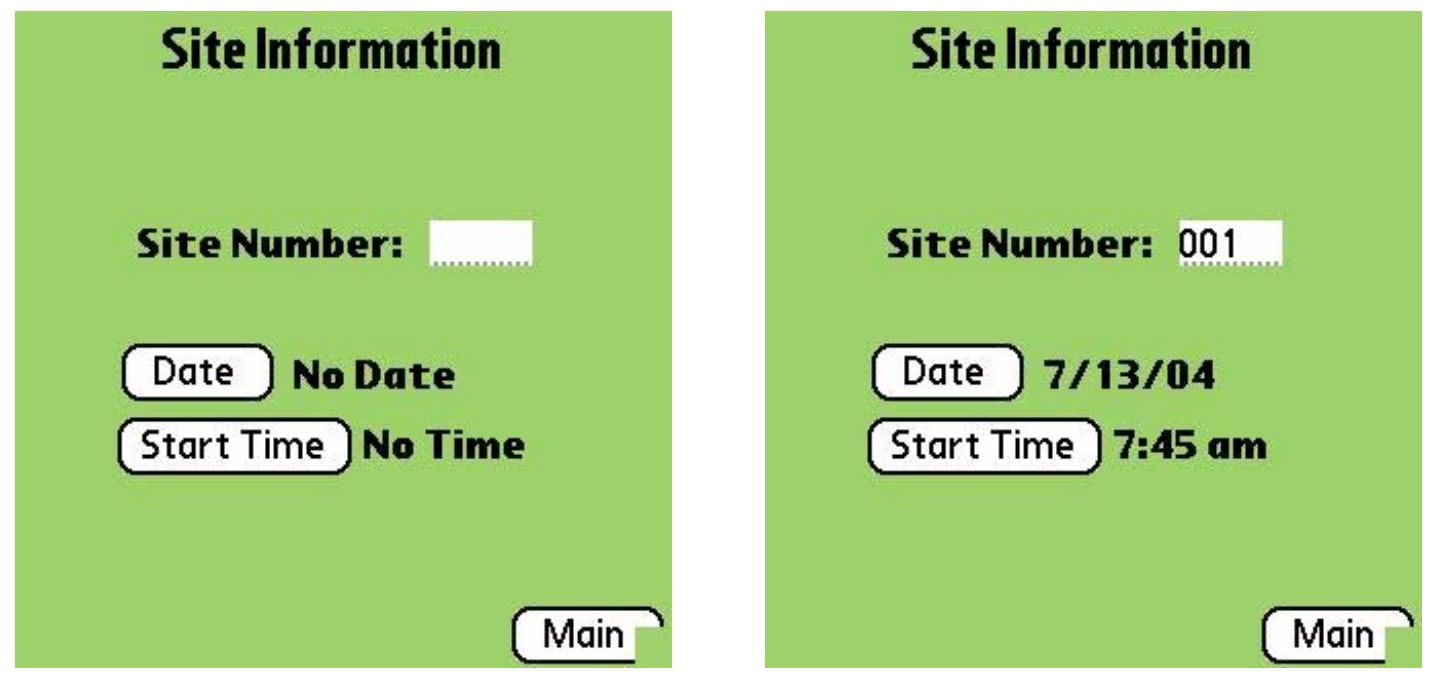

Figure 1. Start information for each site. 
Once the descriptive information had been entered, observers tapped on the "main" button to go to the main screen within the booster seat use file for that site (see Figure 2). At this point, observers began looking into vehicles for target-aged children. When an eligible vehicle was identified, the observer used the PDA stylus to tap on the "driver" button. On the driver screen, observers entered the safety belt use, age, and sex of the driver by tapping on the appropriate choices from the displayed lists (Figure 3). If a mistake was made, the observer could change the data they had input by tapping on the correct choice. All selected choices appeared highlighted on the screen. When the driver information was complete, the observer once again tapped on the "main" button to return to the main screen.

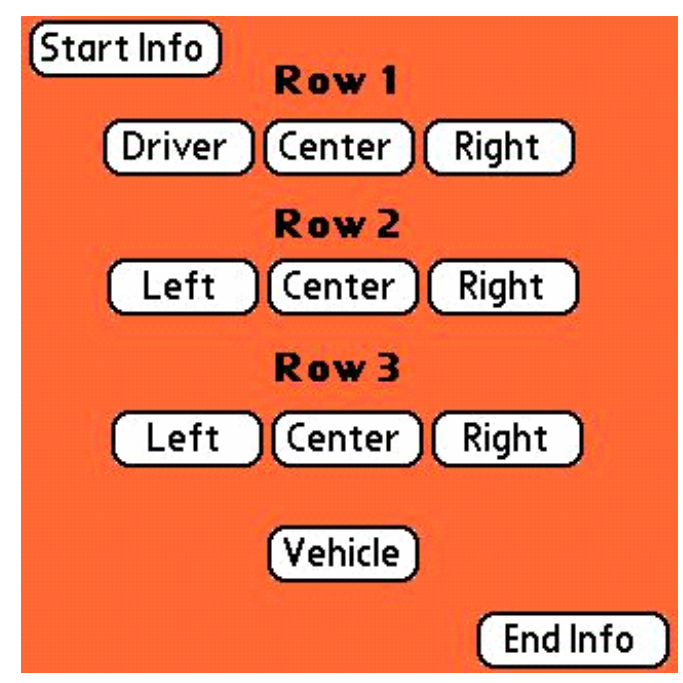

Figure 2. Main screen within booster seat use form. 


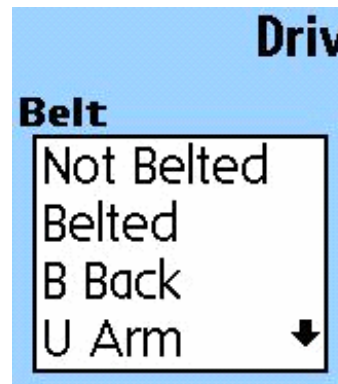

\section{Sex}

Male Female PrevVeh
Age

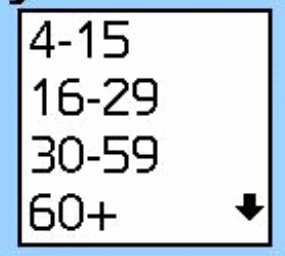

$60+$

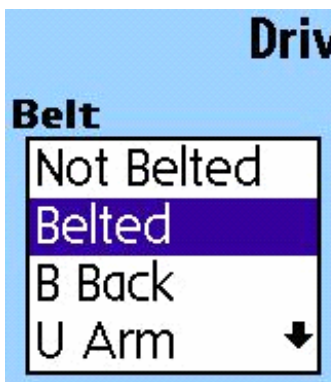

Sex

Male Female

Prev Veh
Main

Figure 3. Driver screen within booster seat use form.

As shown in Figure 2, observers tapped on the appropriate seating position displayed on the main screen to enter data about the target-aged child. The resulting screen allowed the user to enter the restraint use and sex of the child by tapping on the appropriate choices (see Figure 4). Once the data for the target-aged child was entered, the observer returned again to the main screen. If another target-aged child was present, the observer continued by tapping on the appropriate seating location for each subsequent child, and then entering the restraint use and sex. If no other targetaged children were observed in the vehicle, the observer returned to the main screen and tapped on the "vehicle" button. On the vehicle screen, observers entered the vehicle type, then continued data collection by tapping on the "next vehicle" button (see Figure 5). 

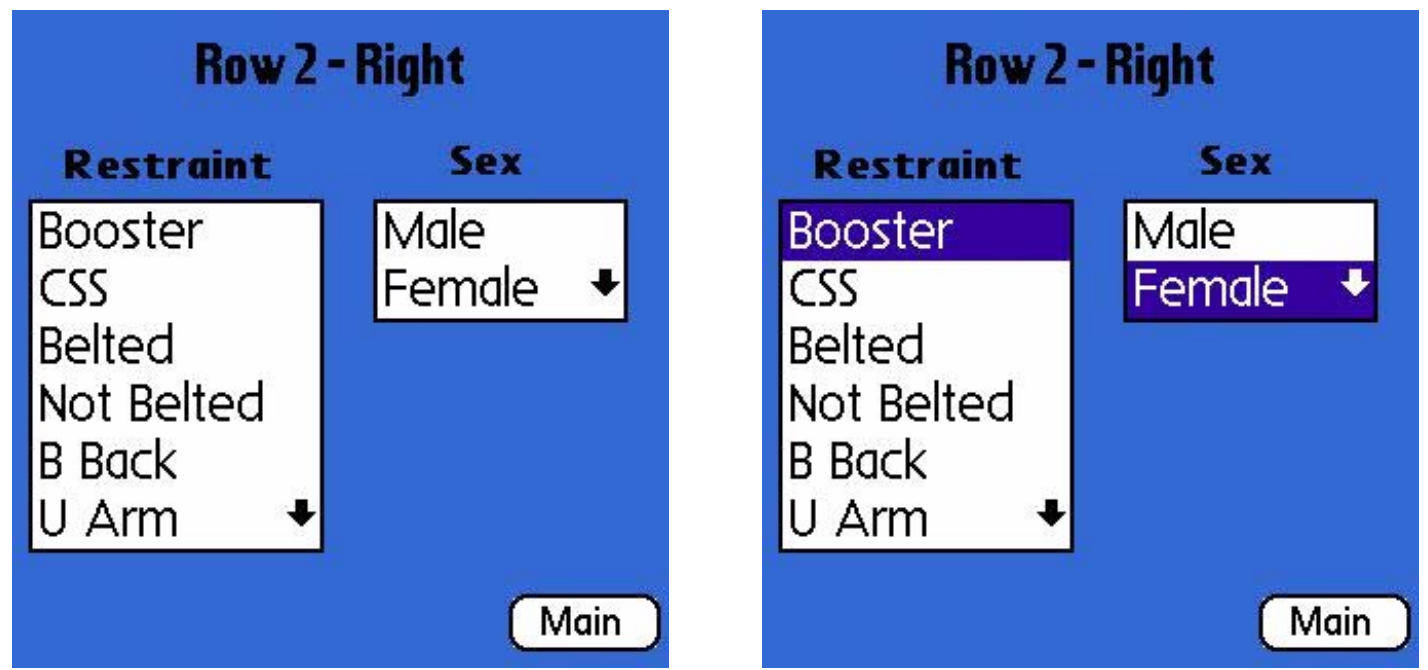

Figure 4. Target-aged child example screen.
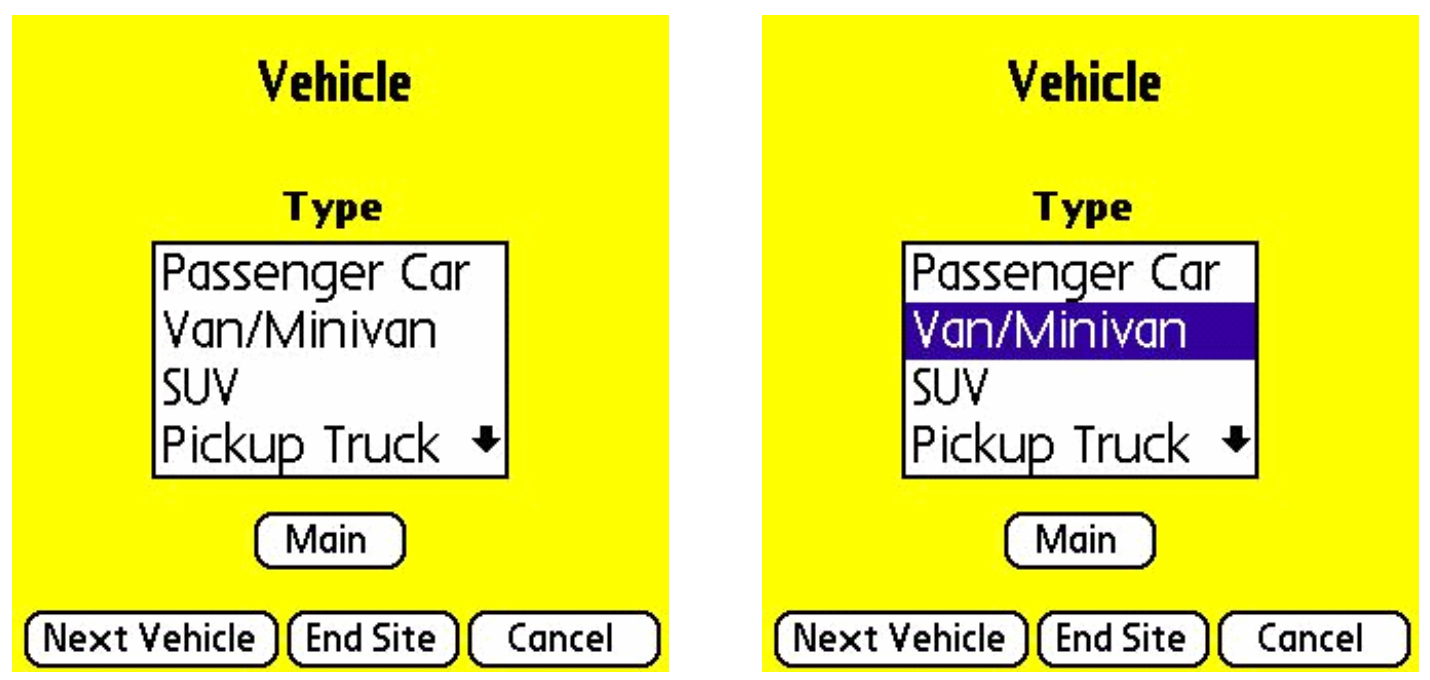

Figure 5. Vehicle screen within booster seat use form.

When the data collection period ended, observers tapped on the "end info" button on the main screen. This opened the site information screen for the end of the site (see Figure 6), where observers entered the end time and any comments relevant to data collection. Finally, observers ended data collection at the site by tapping on the "end site" button. 

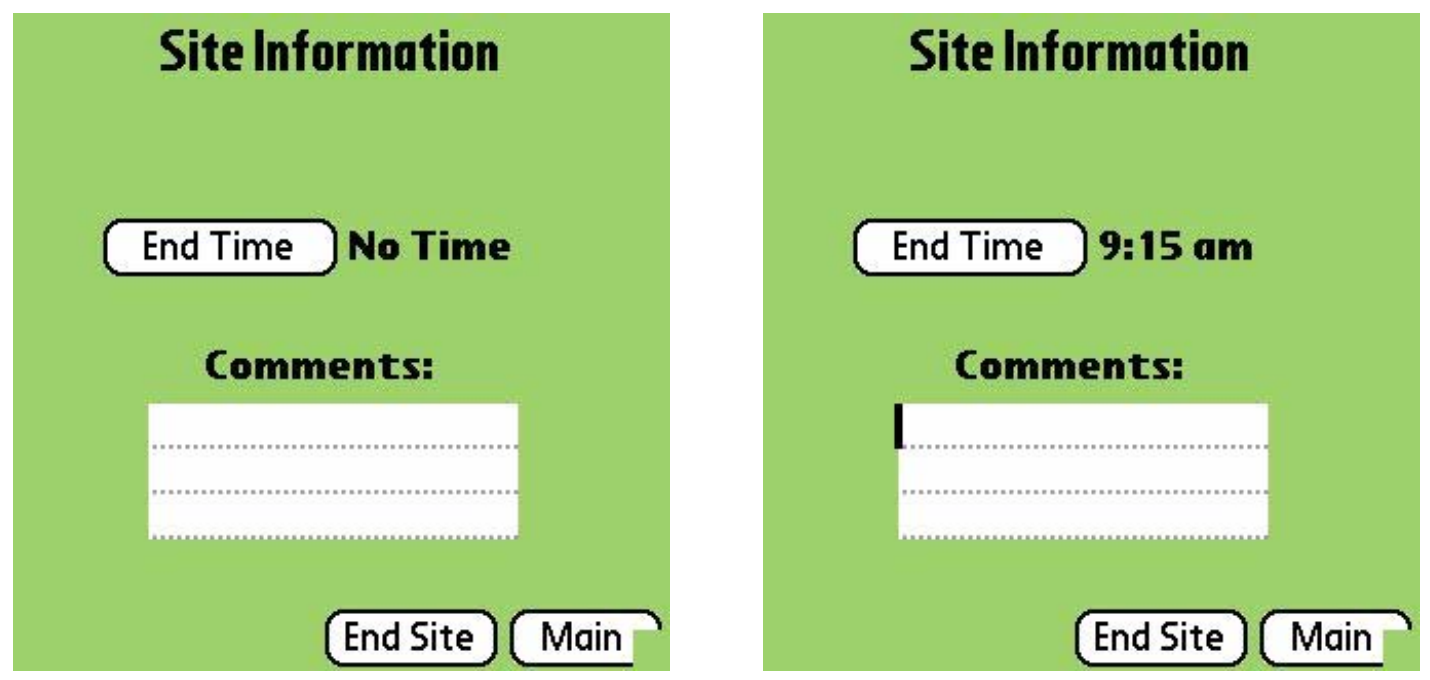

Figure 6. Site information end screen within booster seat use form.

Each PDA also had a built-in cellular phone as well as wireless e-mail capability. At regular intervals, usually twice a day, observers e-mailed completed data directly from the PDA to the project supervisor. Booster seat use forms from completed sites were "zipped," using a compression program, and then transmitted directly to a preconfigured e-mail account. The e-mailing of data allowed the field supervisor to immediately check data for errors, and begin to compile a data analysis file as the project progressed. After data transmission, the observer transferred the site data from the internal memory of the PDA to a Secure Digital (SD) memory card. 


\section{APPENDIX B}

Training Manual 


\title{
Direct Observation of Booster Seat Use \\ Training Manual - July 2004
}

\author{
University of Michigan \\ Transportation Research Institute \\ Social and Behavioral Analysis Division \\ 2901 Baxter Rd., Ann Arbor, MI 48109-2150
}

(734) 763-2466 


\section{Table of Contents}

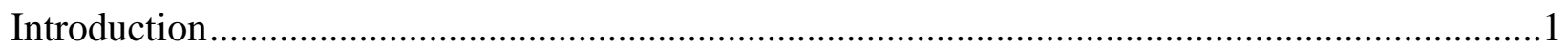

Administrative Policies and Procedures ..........................................................................2

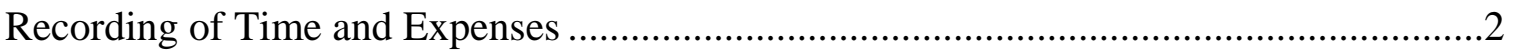

Food Allowance for Overnight Trips....................................................................

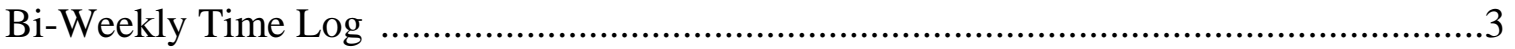

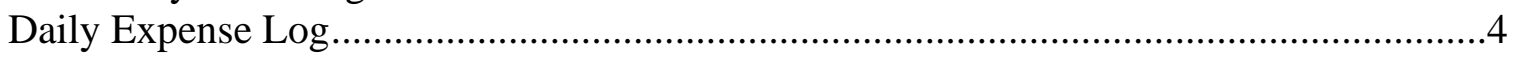

Field Procedures.........................................................................................................

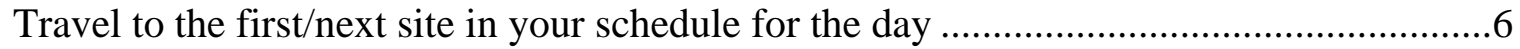

Determine where to stand in order to conduct observations .........................................

Record the time and date; observe vehicles, and record data .........................................8

Detailed instructions for observing booster seat use......................................11

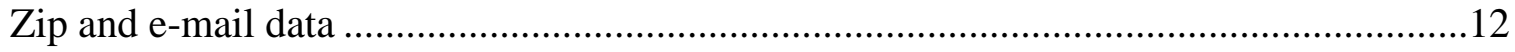

Return to UMTRI and check supplies and observer schedule ......................................12

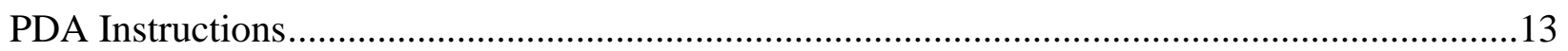

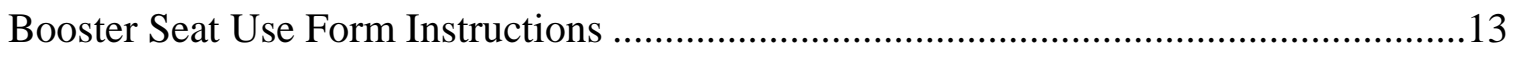

At the end of the data collection period .......................................................... 14

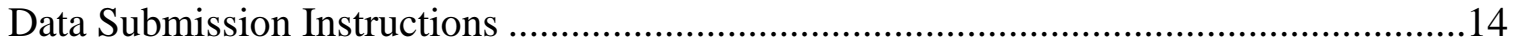

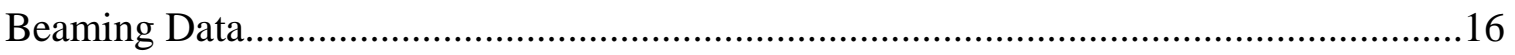

Creating New Booster Seat Use Form Files From the Backup File .................................16

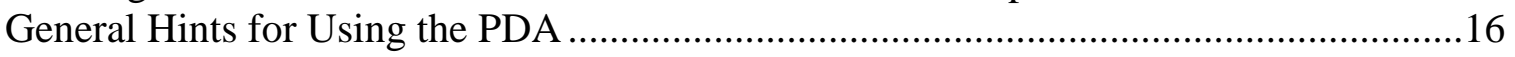

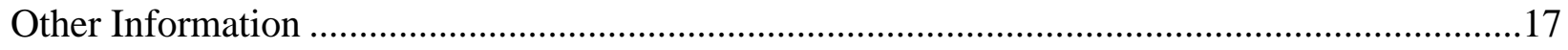

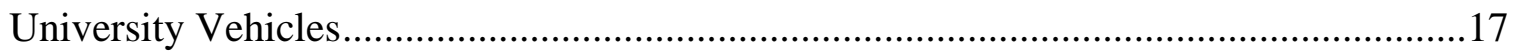

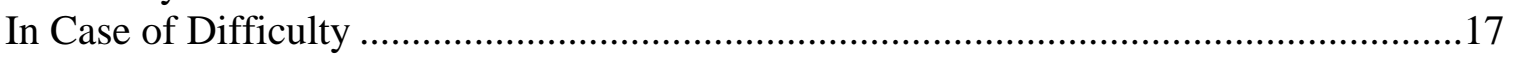

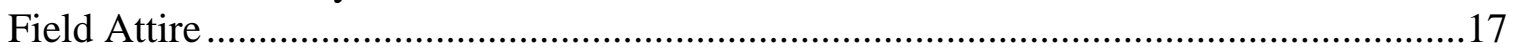

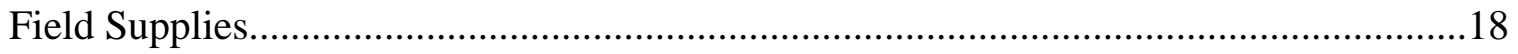

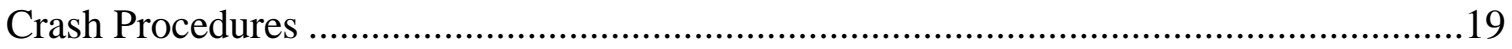

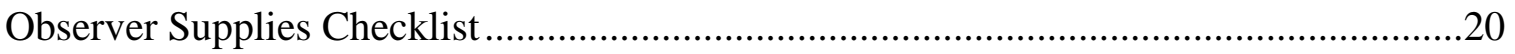

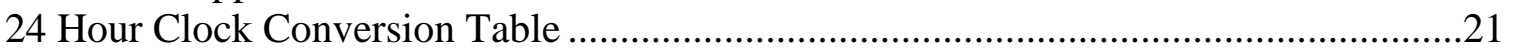




\section{Introduction}

The primary purpose of this study is to observe booster seat use by 4 to 8 year old children in passenger cars, vans/minivans, sport-utility vehicles, and pickup trucks in Michigan in order to develop more effective programs to promote the proper use of these seats. Booster seat use data will be collected through direct observation.

Study protocols for data collection are described in this manual. Relevant University of Michigan administrative policies and procedures are also included.

Adherence to study protocols is critical to ensure reliability in the data collection process. In order to maintain consistency among observers, the study is designed to minimize the number of decisions you must make in the field. When decisions are required, specific guidelines are provided for you to follow.

If you have any suggestions for improving the training or data collection process, please save them until the end of the study. There will be a debriefing session to evaluate your training and field experience after data collection has been completed. 


\section{Administrative Policies and Procedures}




\section{Administrative Policies and Procedures}

\section{Recording of Time and Expenses}

\section{Bi-Weekly Time Log}

Each observer is responsible for completing a Bi-Weekly Time Log (see example on page 3). Record your name and the weeks covered by the log. Then, for each day, record your start time and end time. Please write in pencil and enter all times using a 24 hour clock (military time). Please denote subtotal and total hours in the format of Hours:Minutes. When leaving from UMTRI, your start time will begin with your preparations for leaving for the field. This might involve such activities as checking and loading supplies, maps, etc. When on an overnight trip, your start time is upon departure from the hotel and end time is when you arrive at the hotel. Meal breaks are unpaid - meaning on your own time.

\section{Daily Expense Log}

Each observer is responsible for completing a Daily Expense Log (see example on page 4). It is important that this log be filled out accurately with times and expenses, and that you keep all receipts for your expenses. Turn logs in daily whenever possible. This will allow us to check them and find any errors as early as possible.

\section{Food Allowance for Overnight Trips}

For overnight trips only, there is a daily food allowance for each day in the field. The State of Michigan meal budget is as follows:

$\begin{array}{ll}\text { Breakfast } & \$ 7.25 \text { including no more than } 20 \text { percent tip } \\ \text { Lunch } & \$ 7.25 \text { including no more than } 20 \text { percent tip } \\ \text { Dinner } & \$ 16.50 \text { including no more than } 20 \text { percent tip } \\ \text { Total } & \mathbf{\$ 3 1 . 0 0} \text { including no more than } 20 \text { percent tip }\end{array}$

Any costs above these amounts for each meal are your own expense. Averaging between days is not permitted. For example, if one day's total comes to $\$ 25.00$ including tip, the rest of the meal allotment cannot be applied to any other day. However, averaging between meals on the same day is permitted as long as the $\$ 31.00$ per day amount is not exceeded. Please remember, receipts for all meals are required. The tip amount should be written on the meal receipt, and should not exceed 20 percent. Note: Reimbursement for alcoholic beverages is not allowed.

Hotel reservations have been made for trips requiring overnight travel. The itemized receipt (folio) from the hotel is required, not just a charge slip. Only the room rate is covered: movies and personal telephone calls, etc. will not be reimbursed. Information will be provided separately on location, room rate, telephone number, etc. If anyone will be staying at the hotel with you, you must get prior permission from one of the project supervisors. 
Bi-Weekly Time Log

Employee:

Project \#:

NOTE: Please use a 24 hour clock and write in pencil.

Weeks of:

/2004 to

/2004

\begin{tabular}{|c|c|c|c|c|c|c|c|c|}
\hline $\begin{array}{l}\text { D } \\
\text { A } \\
\mathbf{Y}\end{array}$ & $\begin{array}{l}\mathbf{D} \\
\mathbf{A} \\
\mathbf{T} \\
\mathbf{E}\end{array}$ & Time In & Time Out & $\begin{array}{l}\text { SUBTOTAL } \\
\text { HOURS }\end{array}$ & Time In & Time Out & $\begin{array}{c}\text { SUBTOTAL } \\
\text { HOURS }\end{array}$ & $\begin{array}{l}\text { TOTAL } \\
\text { HOURS }\end{array}$ \\
\hline $\begin{array}{l}\mathbf{S} \\
\mathbf{U} \\
\end{array}$ & & & & & & & & \\
\hline $\begin{array}{l}\mathbf{M} \\
\mathbf{0}\end{array}$ & & & & & & & & \\
\hline $\begin{array}{l}\mathbf{T} \\
\mathbf{U} \\
\mathbf{E}\end{array}$ & & & & & & & & \\
\hline $\begin{array}{l}\text { W } \\
\text { E } \\
\text { D }\end{array}$ & & & & & & & & \\
\hline $\begin{array}{l}\mathbf{T} \\
\mathbf{H} \\
\mathbf{U}\end{array}$ & & & & & & & & \\
\hline $\begin{array}{l}\mathbf{F} \\
\mathbf{R} \\
\mathbf{I}\end{array}$ & & & & & & & & \\
\hline $\begin{array}{l}\text { S } \\
\text { A } \\
\text { T }\end{array}$ & & & & & & & & \\
\hline $\begin{array}{l}\mathrm{S} \\
\mathbf{U} \\
\mathbf{N}\end{array}$ & & & & & & & & \\
\hline $\begin{array}{l}\text { M } \\
\text { O } \\
\mathbf{N}\end{array}$ & & & & & & & & \\
\hline $\begin{array}{l}\mathrm{T} \\
\mathrm{U} \\
\mathrm{E}\end{array}$ & & & & & & & & \\
\hline $\begin{array}{l}\text { W } \\
\text { E } \\
\text { D }\end{array}$ & & & & & & & & \\
\hline $\begin{array}{l}\mathbf{T} \\
\mathbf{H} \\
\mathbf{U}\end{array}$ & & & & & & & & \\
\hline $\begin{array}{l}\mathbf{F} \\
\mathbf{R} \\
\mathbf{I}\end{array}$ & & & & & & & & \\
\hline $\begin{array}{l}\text { S } \\
\text { A } \\
\text { T }\end{array}$ & & & & & & & & \\
\hline
\end{tabular}


EMPLOYEE:

DATE

$/ 2004$

PROJECT \#:

BREAKFAST \$

LUNCH \$

DINNER

$\$$

GASOLINE

$\$$

OTHER (describe) \$

OTHER (describe) \$

OTHER (describe) \$

OTHER (describe) \$

TOTAL \$

IMPORTANT: EXPENSES CAN ONLY BE REIMBURSED IF A RECEIPT IS INCLUDED. SAVE AND ATTACH ALL RECEIPTS FOR EVERY EXPENSE!

* Please also attach itemized receipt from hotel.

Attach

receipts

here. 


\section{Field Procedures}




\section{Field Procedures}

All observers will travel in teams of two for this study. For most sites in the study, both observers in the team will collect data at the site. On occasion, however, the teams will split up and observe two different nearby sites at the same time. In these cases, one observer will be dropped off at the site for data collection and picked up afterwards by the second observer. Regardless of whether there is one or two observers at the site, the field procedures followed will be the same.

There are three types of sites in this study: Day-care centers, McDonald's restaurants, and shopping centers/grocery stores. These sites have been selected because they have a higher concentration of target-aged (4 to 8 year old) children in vehicles than other sites. In order to maximize our chances of observing target-aged children, day care centers will always be observed during the morning drop-off period (7:45 AM - 09:15 AM); McDonald's sites will nearly always be observed during a mealtime (usually around the lunch hour), and shopping sites will be observed in the mornings and afternoons.

There are 5 steps that comprise the basic procedures followed at all sites.

For now, it is important to understand the general steps that need to be followed to collect data at each site. They are:

1. Travel to the first/next site in your schedule for the day.

2. Determine where to stand to conduct observations.

3. Record the site number, date, and start time; observe vehicles, and record data using the appropriate Booster Seat Use Form file for the time period scheduled.

4. When time permits, zip and e-mail data to the project supervisor.

5. After the last site of the day, return to UMTRI and check supplies and observer schedule for the next work day.

The next few pages explain each step in detail. The details will also include any other study protocols which must be adhered to in order to ensure quality data collection and consistency among observers. 


\section{Travel to the first/next site in your schedule for the day.}

If it is the first site of the day:

- It is important that you begin each day of observations at the start time scheduled for the first site. The first site of the day is nearly always a day-care center. Our goal is to observe the day-care center during its morning drop-off period. Each day care site is $\mathbf{1 . 5}$ hours long to ensure that we cover the majority of period. As such, it is important to be at the site on time. Give yourself enough time for travel, taking into account possible construction or traffic and whether or not one of the observers needs to be fist dropped off at a site. After the first site, the remaining start-times are guidelines.

After the first site:

- Travel time has been taken into account in making up this schedule. However, experience has shown us that unexpected travel delays due to traffic, road construction, missing road signs, trains, etc., can keep you from starting observations at the scheduled times.

- $\quad$ All observations are to be completed before dark. If delays keep you from completing observations at sites scheduled for a particular day before dark, complete the "Start Info" and "End Info" sections of the appropriate Booster Seat Use file for each site not observed and note, in the comments section, why observations were not made (e.g., because of travel delays).

If you arrive at any site early:

- If you arrive at any site early, do not begin observations until the time scheduled for that site. If you should fall behind schedule, continue observing sites in the order and length of time listed on the schedule even though you may end up observing some sites later than scheduled.

\section{Parking:}

- Do not use the parking lot of the establishment that is the site, even if this means that you have to walk a short way from the parking area to the site. It is also important that you do not park where traffic will be obstructed. 


\section{Determine where to stand in order to conduct observations.}

Our goal in this study is to observe as many target-aged children as possible at each site. For most of the sites there will be several entrances. You should take a moment to determine which entrances vehicles coming to the site are most likely to use, and position yourself at the one (for a single observer sites) or two (for two-observer sites) main or potentially busiest entrances.

You should stand near the curb on the public sidewalk or grass area next to the site entrance. In order to get the best angle of view into the vehicle, stand the left side of the entrance (when viewed from the Day Care Center, etc.) so that you can look into the passenger-side of vehicles as they enter sites.

If there is only one entrance and two observers for the sites, as may happen at some of the daycare center locations, you should do the following. Both observers should stand at the same location and alternate recording data from vehicles. It is important that you collect information from different vehicles so that we do not "double-count" information. For this method to be effective, observers must communicate with each other to determine who will collect data from which vehicle. 


\section{Record the start/end time and date; observe vehicles, and record data in the appropriate Booster Seat Use file for the number of minutes scheduled.}

The Booster Seat Use Form will be used to gather booster seat use information for target-aged passengers and driver safety belt information, as well as demographic information.

- $\quad$ Before you begin gathering data, make sure that you have opened the appropriate Booster Seat Use Form file in HanDBase.

- $\quad$ Record the site number, start time, and date (although the buttons appear on the "Main" screen for every vehicle for which you collect data, you only need to enter these data for the first one).

- Observe vehicles for target-aged children. For each vehicle with at least one target-aged child (4-8 years of age), record the driver's belt use, sex, age, all target-aged passenger's restraint use and sex, and the vehicle type using the appropriate Booster Seat Use Form file in HanDBase. Complete recording data for one vehicle before going on to the next. Continue this process throughout the observation period. Note that older and historic vehicles do not have shoulder belts; do not record driver safety belt use for these vehicles.

- If you are unsure of whether the driver or target-aged passenger is restrained, use your best judgement and tap the appropriate category. Do not leave blank. We realize that there will be situations in which you will not be $100 \%$ sure of what you are seeing in the car. Research shows that people can still make accurate judgments under conditions of less than $100 \%$ certainty. Therefore you are to make your best judgment even when you are not completely certain. If you cannot see anything in the car (because of completely darkened windows, etc.), then you have no information on which to make your judgment and you should go on to the next car.

- At the end of the observation period, record the end time and any comments related to the site.

The following page explains in detail each category of data that you will be collecting. These data will be recorded using the Booster Seat Use Form. Again, specific instructions for collecting data using the electronic Booster Seat Use Form file are included later in the manual. 


\section{Observation (BoostUse) Form Categories:}

- $\quad$ Site Information categories are as follows:

- $\quad$ Site number: record the number of the site you are at. The number should be between 001-176.

- $\quad$ Date: enter the actual date on which observations take place.

- $\quad$ Start time: enter the actual start time for observations.

- $\quad$ End time: enter the actual end time for the observations

- Driver categories are as follows:

- Belt Use:

- $\quad$ Not Belted: the driver is not restrained by a shoulder belt

- $\quad$ Belted: the driver is properly restrained by a shoulder belt

- $\quad$ B Back: the driver has the shoulder strap behind his or her back

- U Arm: the driver is restrained by a shoulder strap, but the strap is under the arm

- $\quad$ Age:

- $4-15$

- $16-29$

- $\quad 30-59$

- $60+$

- Sex:

- $\quad$ Male

- $\quad$ Female

- $\quad$ Target-Aged Passenger categories are as follows:

- Restraint:

- $\quad$ Booster: the target-aged passenger is placed in a belt-positioning booster seat that is either high-back, no-back, or a shield type.

- $\quad$ CSS: the target-aged passenger is placed in a toddler or infant seat. These are distinguished by the presence of a harness.

- $\quad$ Belted: the target-aged passenger is properly restrained by a shoulder belt

- $\quad$ Not Belted: the target-aged passenger is not restrained by a shoulder belt

- $\quad$ B Back: the target-aged passenger has the shoulder strap behind his or her back

- $\quad$ U Arm: the target-aged passenger is restrained by a shoulder strap, but the strap is under the arm

Sex:

\section{- $\quad$ Male}

- $\quad$ Female 
NOTE: Record the target-aged passenger information for ALL target-aged passengers by using the button associated with the proper seating positions.

- $\quad$ Vehicle categories are as follows:

- $\quad$ Passenger Car: those vehicles that are primarily intended to carry passengers, and includes coupes, sedans, convertibles, and station wagons. The Chrysler PT Cruiser is included in this category.

- $\quad$ Van/Minivan: both full size and mini-vans.

- $\quad$ SUV: vehicles such as the Jeep, Lincoln Navigator, Toyota RAV4, or Chevrolet Tracker, as well as the GM/Chevrolet Suburban.

- $\quad$ Pickup Truck: full and mini-size trucks having a bed behind the cab. The Ford Explorer Sport-Trac is included in this category. 


\section{Detailed instructions for observing booster seat use at all types of sites.}

As a vehicle enters a site, look for target-aged passengers. If there are no passengers of the appropriate age, then ignore the vehicle. If there is one or more target-aged passenger then take note of their restraint use and sex. Then determine the driver's restraint use, sex, and age. Record this information into the appropriate places on the Booster Seat Use form on the PDA. While this may seem like a lot of information to acquire in a short amount of time, with practice, most of this information can be determined with a quick glance. The most difficult, and most important, information will be distinguishing between booster seats and the other types of child safety seats (toddler and infant) and seeing the "no-back” type of booster seat.

Once you have recorded information from one vehicle, record information from the next vehicle you see with target-aged children. If traffic volumes are high, do not worry about getting information from all vehicles. It is better to get complete and accurate information from one vehicle before going onto the next.

People may stop and ask who you are working for or what you are doing. Tell them that you are doing a traffic safety study for the University of Michigan.

Owners or supervisors of establishments may be concerned by your presence and they may ask you to leave. If so, politely explain the following:

- $\quad$ You are conducting a traffic safety study for the University of Michigan.

- $\quad$ You are not collecting any identifying information.

- $\quad$ You are not talking to customers or disrupting traffic.

- You are standing on a public right-of-way.

- $\quad$ You may also give them Dr. Eby’s business card.

- $\quad$ You may show them the letter of support from MDCH.

Most people will accept this explanation. If they persist that they do not want you there, then leave and call the field supervisor to explain the situation. 


\section{Zip and e-mail data to the project supervisor.}

When time permits, zip and e-mail data to the project supervisor. See PDA instructions later in the manual for a description of these procedures.

\section{After the last site of the day, return to UMTRI and check supplies and observer schedule for the next work day.}

After the last site of the day, observers will return to UMTRI, unless on an overnight trip. If returning from an overnight trip, leave completed Daily Expense Logs in the back of the staff car in the box marked "Completed Data Forms." It is important that Daily Expense Logs are completed quickly so that University credit card statements and cash advance forms can be reconciled. Please be aware of due dates for Bi-Weekly Time Logs, and leave these in the staff car when appropriate.

While preparing for the next day, each observer should check their supplies to make sure that there are enough for the next work day. Also check your schedule for the next day to determine what time you have to arrive at UMTRI to meet your observer partner, so that you can get to the first site of the day on time. Finally, make sure that your car has been refueled. 


\section{PDA Instructions}

Turn on the PDA. Open HanDBase by tapping on the HanDBase symbol (see below) or using

the

calendar quick key.

\section{s \\ HanDBase 3}

\section{Booster Seat Use Form Instructions}

Select the correct site number from the list and open by tapping the file name to highlight it and then tapping the "open" button (or tapping the file name twice). The sites are named so that the first number corresponds to the day of the study, the second number denotes the order of the sites in the day, and the third number is the three-digit site number. This way, the sites are listed in the order they should be done.

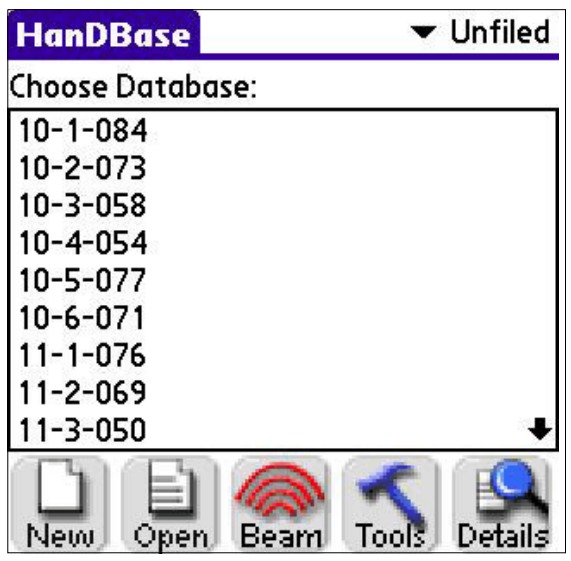

The program will open on a blank Booster Seat Use Form list. Tap the "New" button to begin entering data. The first screen asks for driver information. Tap the appropriate categories that correspond to the belt use, sex, and age of the driver. Once the driver information has been entered, tap the "Main" button on the bottom right. The "Main" screen shows all 9 of the possible seating positions in a vehicle. Tap the appropriate button that corresponds to the location of the target-aged child in the vehicle. Select the restraint use and sex of the child, then return to the main screen. If there are more target-aged children in the vehicle, note this by tapping on the corresponding seating locations for each child and selecting their restraint use and sex. To finish, tap on the vehicle button, and enter the proper vehicle type.

If you need to, you can flip between the any of the screens by tapping on the appropriate button on the main screen. The screens can be done in any order, but you must return to the vehicle screen to submit or cancel the data. Once you have completed data collection for all target-aged children in the vehicle, as well as the driver and vehicle type, tap the "Next Vehicle" button to continue collecting data. 
If you make a mistake, but have already tapped the "Next Vehicle" button, you can go back by tapping the "Prev Veh" button on the driver page. This will take you to the "Edit Record" screen. To change the data, simply tap on the category to display the choices, then tap on the correct data. When you are done, tap on the "New" button to continue collecting data.

For the first vehicle and the last vehicle at the site, enter the start and end times, the date, and any comments related to data collection at the site. These data can be entered by tapping on the "Start Info" and "End Info" buttons on the main page. During data collection for the first vehicle, tap on the start info button and enter the site number by tapping in the text entry box. A numerical pop-up screen will appear. Type in the appropriate 3-digit site number. To enter the date, tap on the "Date" button and tap "Today" on the pop-up screen. Enter the start time by tapping on the "Start Time" button, then tapping the appropriate time from your stopwatch. During data collection for the last vehicle at the site, tap on the end info button and enter the end time in the same way as the start time. Also enter any comments relevant to data collection by tapping in the comments field and then typing the appropriate comments. This field should be used to describe any problems at the site as well as if BOTH you and your observer partner do not collect data from any children at the site. In the event that you do not observe any target-aged children throughout the entire data collection time, notify the project supervisor as soon as possible.

At the end of the data collection period:

If you have entered data for the vehicle displayed on your screen (or if you have entered an end time and/or comments), tap the "End Site" button. If you have not entered anything for this vehicle, tap the "Cancel" button. Both of these buttons will return you to the list of vehicles.

From here tap the "Home" button. You will now be returned to the list of databases and can choose the appropriate file for the next site.

\section{Data Submission Instructions}

Open the HandZipper application by tapping on the "HandZipper." symbol (see below).

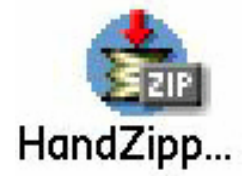

\begin{tabular}{|c|c|}
\hline Database List & Zip Unzip \\
\hline 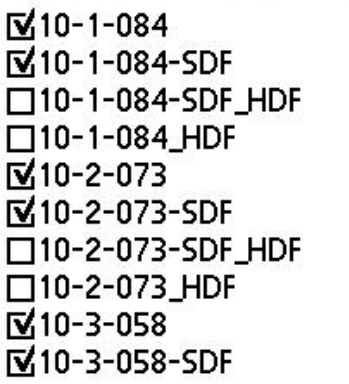 & $\begin{array}{l}41 \mathrm{~KB} \\
41 \mathrm{~KB} \\
18 \mathrm{~KB} \\
11 \mathrm{~KB} \\
42 \mathrm{~KB} \\
41 \mathrm{~KB} \\
18 \mathrm{~KB} \\
11 \mathrm{~KB} \\
42 \mathrm{~KB} \\
41 \mathrm{~KB}\end{array}$ \\
\hline 6 files & 250KB \\
\hline Zip Zip \& Mail Del & All None \\
\hline
\end{tabular}


All database files on the PDA will appear with an empty checkbox next to the name. Because the data files are named numerically, they will appear at the top of the list. Place a check mark in the box next to the files you wish to zip and e-mail (see image at right). Please note: The files marked with "_HDF" after the name are the data entry form files and should NOT be sent. Once you have all of the files checked that you wish to send, tap the "Zip \& Mail" button. For the Zip file name, enter your initials and the day number (i.e. JVDay10).
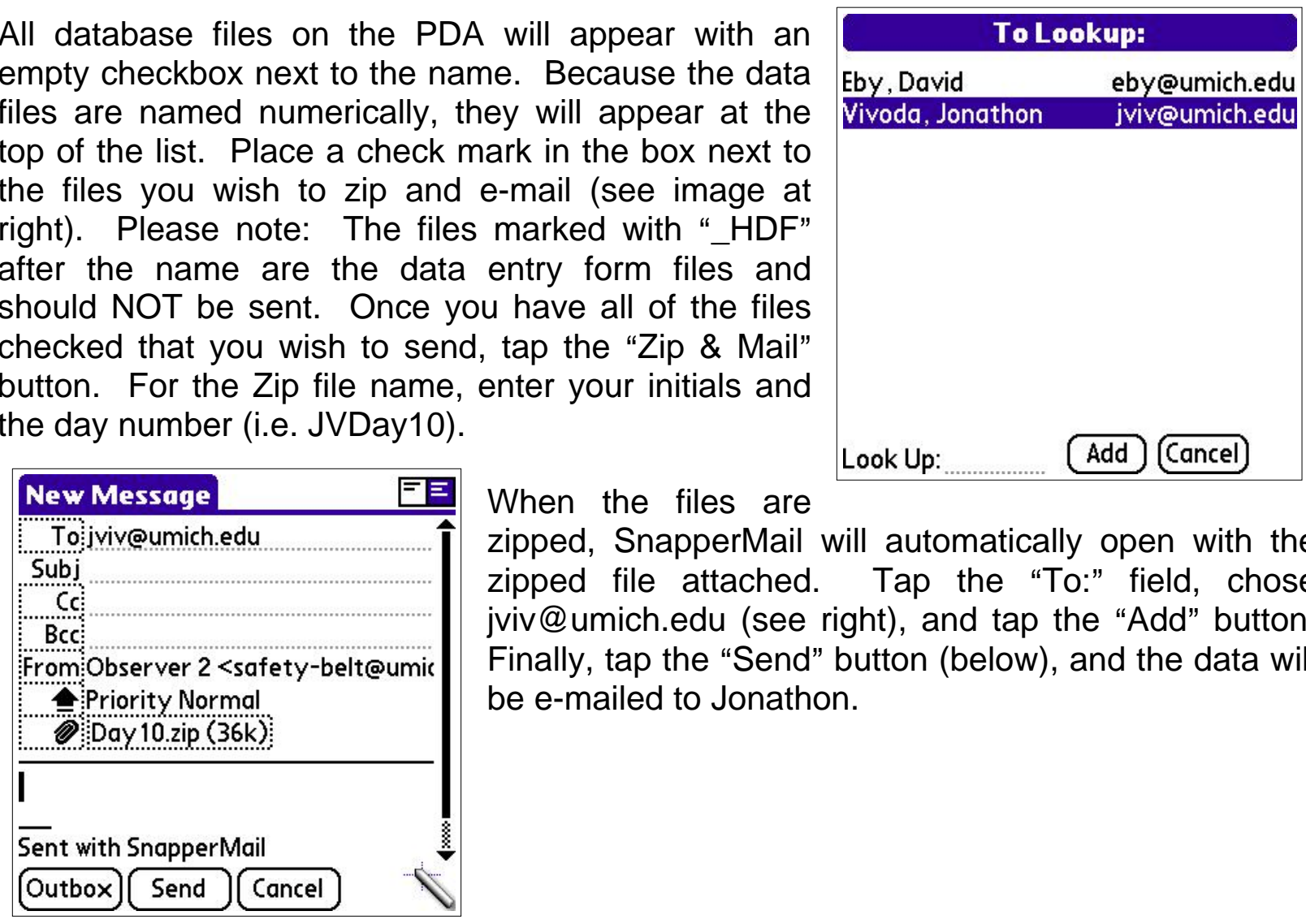

When the files are zipped, SnapperMail will automatically open with the zipped file attached. Tap the "To:" field, chose jviv@umich.edu (see right), and tap the "Add" button. Finally, tap the "Send" button (below), and the data will be e-mailed to Jonathon.

While the data is being transmitted, the screen will change to a bar graph showing the size of the message, how much has been transmitted, and the time remaining for the transmission. It is not unusual for the time remaining to remain unchanged for a minute or longer. Sometimes, if the transmission is interrupted, the screen will not change for many minutes. If this happens, the PDA may need to be reset.

You will not be able to use the PDA for any other function while transmitting data, so send e-mail messages only when you have enough time to complete the transmission before beginning data collection at a new site. Sending a message with an average-sized file attached can take about 5 minutes to complete, so plan accordingly. Try to send data whenever possible: during lunch, a long break, or if you get to a site very early. Also note that when traveling, the transmission is sometimes interrupted, and the message fails to be sent before you need to begin data collection at the new site.

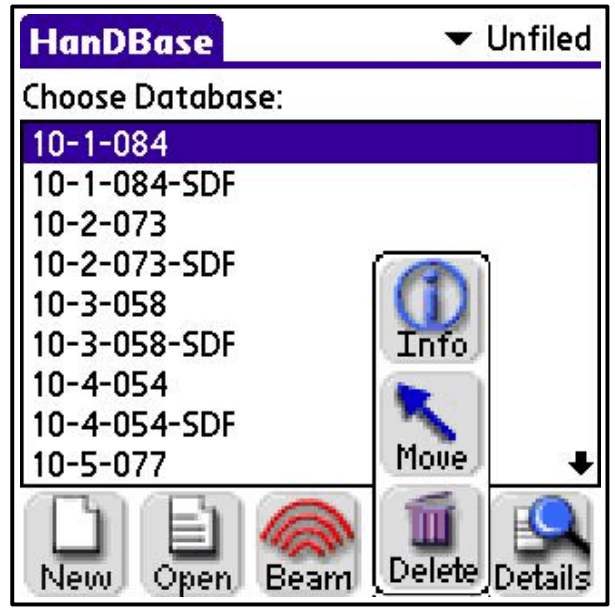


Once you have completed a successful transmission of data (i.e. the data has been successfully e-mailed to Jonathon), move the data file to the expansion SD card that is installed in your PDA. Do this by opening HanDBase as previously described, tap the appropriate site, tap the "Tools" icon, and then tap the "Move" icon (see right). This will not delete the site file, just move it to the SD card's memory instead of the internal memory of the PDA. 


\section{Beaming Data}

Only the Treo PDAs have cellular and e-mail service. If you have a Tungsten PDA, you will need to beam your data to your observer partner so that they can e-mail the data to the project supervisor. This process is similar to moving a file as described above. Tap the appropriate file to highlight it, tap the "Beam" icon, then tap "IR" (infrared). For the file to be beamed, the infrared sensor of the two PDAs must be pointed towards each other and in close proximity. When beaming data, you do not need to send the form to the other PDA. Also note that if you are outdoors when beaming data, you must block the infrared sensors on the PDAs from sunlight so that the beam is not scattered.

\section{Creating New Booster Seat Use Form Files From the Backup File}

If a site file is accidently deleted, or not named properly for the appropriate site, it may become necessary for you to create a new Booster Seat Use Form file. To do this, open HanDBase as described previously, and go to the "Backup" folder by tapping on the drop down menu on the top right of the list of files. Open the "BoostUse" file, and then tap on the name "BoostUse" at the top left of the screen. This action will activate the menu. Next tap on "Actions" and then "Copy Template." Next to "Database Name" type in the appropriate site name (i.e. 01-01-059), then change the category to the appropriate one by tapping on the drop down menu where it says "Backup." Finally, tap "OK" to create the file. Tap OK two more times to get through the file creation screens, and you will now be in the beginning screen of the file you just created. At this point, you can begin collecting data by tapping the "New" icon, or go to the list of databases by tapping the "Home" icon.

\section{General Hints for Using the PDA}

On bright days, turning the screen of the PDA to reflect the sun will result in the brightest image.

If the PDA becomes entirely unresponsive, and needs to be reset, there is a pin in the tip (Treo) or handle (Tungsten) of the stylus. Unscrew the appropriate end of the stylus, and insert the pin in the small hole on the back of the PDA. This will cause the unit to reboot, which takes a few minutes. Whatever data you have entered will be saved by the program, but if the data for the last vehicle was incomplete, it will be recorded that way. 


\section{Other Information}

\section{University Vehicles}

You are representing the University of Michigan. Be aware that the public is watching your personal behavior as well as your driving behavior. There are a few restrictions in the use of University of Michigan vehicles to which you must adhere. Vehicles are to be used for business purposes only and are to be returned to the UMTRI parking lot at the end of the work day. If working out of the area or on an overnight trip, we realize that you will need the vehicle to find a restaurant or hotel, etc. For overnight trips and/or periods of large gaps of time between sites during the day, using the vehicle to visit locations that may reflect unfavorably on the University is prohibited.

Safety belt use in the vehicles is required. Adherence to all driving laws is mandatory, including speed limits on all highways. Driving after drinking is not acceptable, nor is having alcoholic beverages in the vehicle. Failure to adhere to any policy stated will result in disciplinary action.

As an UMTRI employee, you are the only one authorized to drive the vehicle. If any nonUniversity people will be in traveling in the vehicle with you, either on an overnight trip or a day trip, you must get prior permission from one of the project supervisors.

\section{In Case of Difficulty}

If problems or questions arise, call the main office (734) 763-2466, Jonathon (xxx) xxx-xxxx or Dave (xxx) xxx-xxxx, between 8:00 a.m. and 5:00 p.m., Monday-Friday. During evening hours and weekends, call Jonathon at (xxx) xxx-xxxx or (xxx) xxx-xxxx or Dave at (xxx) xxx-xxxx.

If a problem should occur with your vehicle, call the office between 8:00 a.m. and 5:00 p.m., Monday-Friday. During evening hours and weekends, call Jonathon or Dave. Have the address and telephone number of your location and the location of the car, if different, ready to give to us. We will report the problem to Transportation Services and call back with instructions. If you are not able to reach Jonathon or Dave, call the Transportation Services Garage at (734) 7642490, between 7:00 a.m. and 12:30 a.m., Monday - Friday. At other times call the Department of Public Safety at (734) 763-1131.

If you should lock yourself out of your car call the local police and ask if they can provide you with help. If they are unable to help call a local locksmith, and get a receipt.

\section{Field Attire}

It is important that you dress comfortably for outdoor work. We advise you to wear comfortable clothes and be prepared for changing weather. We also have full rain gear available. For safety 
purposes we will provide you with an orange safety vest, which you will be required to wear at all times while conducting observations.

\section{Field Supplies}

Each observer will be assigned a container with all supplies inside. The supplies are only for use in the field during data collection. You are responsible for all supplies and equipment. There is a supply checklist in this section of the manual that you can use before each trip to make sure you have everything you need to conduct the observations. If it becomes necessary to purchase more supplies in the field, do so, and retain your receipt for reimbursement. Please note that personal items you purchase cannot be reimbursed, so please plan ahead and bring warm/light clothes, a coat, or rain gear if you feel there is a chance you may need it. 


\section{University of Michigan Crash Procedures}

In the event of an accident, contact the local police first when possible. If there is no injury, remain at the site of the accident until the police arrive, and then follow the procedures listed below. In case of injury, seek treatment immediately at the nearest hospital. Inform the hospital you are covered by the University of Michigan Worker's Compensation. As soon as you are able, complete the following steps:

- $\quad$ File a police report

- $\quad$ Contact the main UMTRI office (734) 763-2466, Jonathon (xxx) xxx-xxxx or Dave (xxx) $\mathrm{xxx}-\mathrm{xxxx}$, between 8:00 a.m. and 5:00 p.m. During evening hours and weekends, call Jonathon at (xxx) xxx-xxxx or (xxx) xxx-xxxx or Dave at (xxx) xxx-xxxx.

- $\quad$ Contact the University of Michigan Department of Public Safety (764) 763-1131.

- $\quad$ Fill out the Driver's Report of Vehicle Damage or Public Incident. This form must be filled out completely. Blank forms can be found in the glove compartment of each vehicle.

- Turn in the Driver's Report of Vehicle Damage or Public Incident to Jonathon or Dave.

The University of Michigan is self-insured. The blue card in the glove compartment is your proof of automobile insurance. Any questions concerning insurance should be directed to the University of Michigan Risk Management Office (734) 764-2200. All repairs of University vehicles must be performed or coordinated through Transportation Services. Please contact the University Garage during the hours of 7:30 a.m. - 12:30 a.m., Monday - Friday. Wrecker service is also available during these hours. Their phone number is (734) 764-2490. Out of town, after hour, or weekend emergency repairs or road service may be reimbursed by taking the appropriate itemized receipts and replaced parts to Transportation Services. When at all possible, outside repairs should be approved in advance by calling the Transportation Services Garage at (734) 764-2490. Warranty papers can be found in the glove compartments of the vehicles. 


\section{Observer Supplies Checklist}

Please make sure you have all of these items before leaving on each trip, and before turning in equipment at the end of the study.

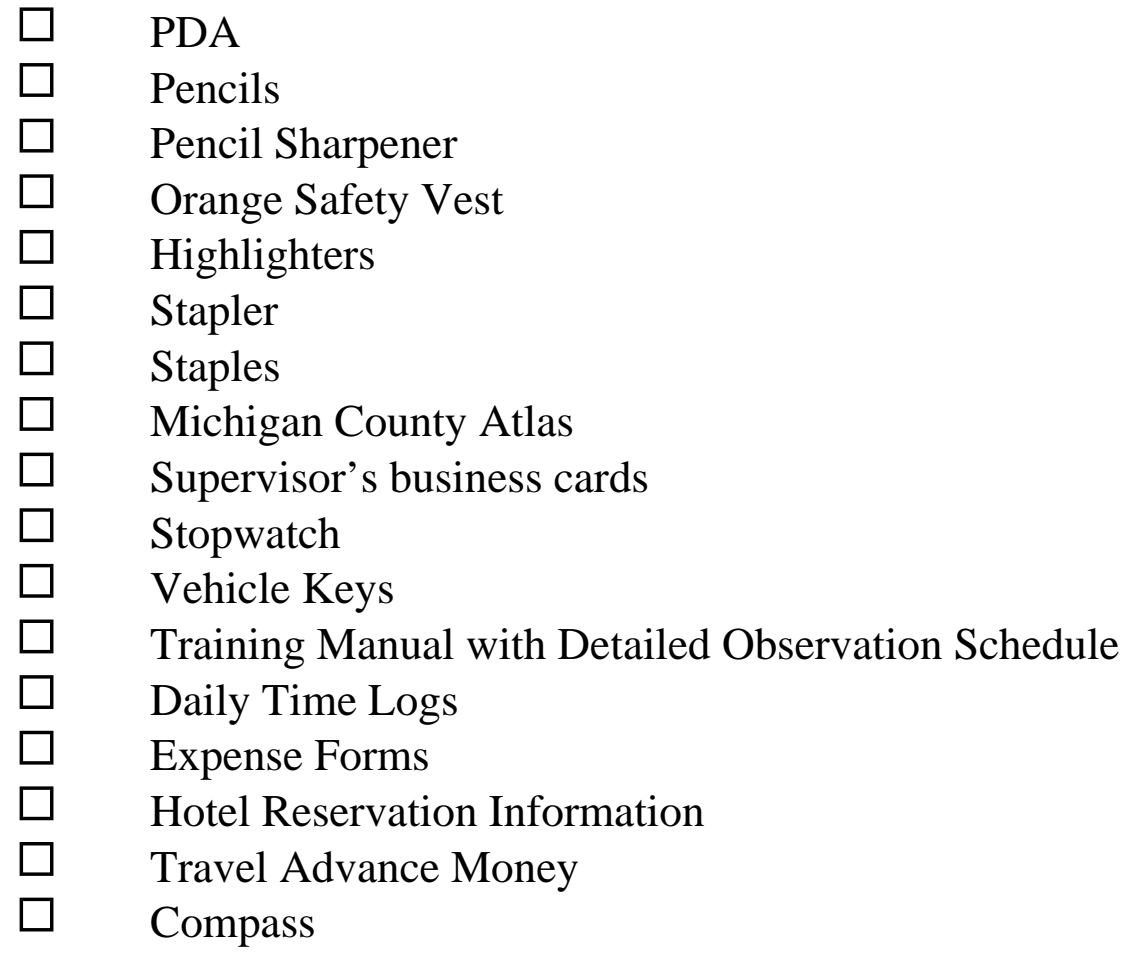

Optional Items:

$\square \quad$ Rain Gear 
24 Hour Clock Conversion Table

\begin{tabular}{|c|c|}
\hline 12 HOUR CLOCK & 24 HOUR CLOCK \\
\hline 1:00 - 1:59 AM & $0100-0159$ \\
\hline 2:00 - 2:59 AM & $0200-0259$ \\
\hline 3:00 - 3:59 AM & $0300-0359$ \\
\hline 4:00 - 4:59 AM & $0400-0459$ \\
\hline 5:00 - 5:59 AM & $0500-0559$ \\
\hline 6:00 - 6:59 AM & $0600-0659$ \\
\hline 7:00 - 7:59 AM & $0700-0759$ \\
\hline 8:00 - 8:59 AM & $0800-0859$ \\
\hline 9:00 - 9:59 AM & $0900-0959$ \\
\hline 10:00 - 10:59 AM & $1000-1059$ \\
\hline 11:00 - 11:59 AM & $1100-1159$ \\
\hline 12:00 - 12:59 PM & $1200-1259$ \\
\hline 1:00 - 1:59 PM & $1300-1359$ \\
\hline 2:00 - 2:59 PM & $1400-1459$ \\
\hline 3:00 - 3:59 PM & $1500-1559$ \\
\hline 4:00 - 4:59 PM & $1600-1659$ \\
\hline 5:00 - 5:59 PM & $1700-1759$ \\
\hline 6:00 - 6:59 PM & $1800-1859$ \\
\hline 7:00 - 7:59 PM & $1900-1959$ \\
\hline 8:00 - 8:59 PM & $2000-2059$ \\
\hline 9:00 - 9:59 PM & $2100-2159$ \\
\hline 10:00 - 10:59 PM & $2200-2259$ \\
\hline 11:00 - 11:59 PM & $2300-2359$ \\
\hline 12:00 - 12:59 AM & $2400-2459$ \\
\hline
\end{tabular}




\section{APPENDIX C}

Site Listing 


\section{Survey Sites By Number}

No. County

Ingham

Ingham

Oakland

Oakland

Oakland

Oakland

Oakland

Oakland

Oakland

Oakland

Oakland

Kalamazoo

Kalamazoo

Oakland

Oakland

Oakland

Oakland

Oakland

Oakland

Washtenaw

Oakland

Washtenaw

Ingham

Oakland

Washtenaw

Washtenaw

Oakland

Oakland

Kalamazoo

Kalamazoo

Kalamazoo

Kalamazoo

Kalamazoo

Oakland

Oakland

\section{Site Location}

Type

Str

Educational Child Care Center 1715 W Main St, Lansing, MI, 48915

Day Care

Bo Peep Day Care Center Cap City Ch Of God, 6228 Bishop Rd, Lansing, MI, 48911 Day Care

Kindercare Learning Center \#1570 3268 Walton Blvd, Auburn Hills, MI, 48326

Day Care

, Farmington Hill, Mr, 48336 Day Care

Children's Learning Center 1109 N Saginaw, Holly, MI, 48442

Rainbow Rascals Learning Ctr 39900 Eight Mile, Northville, MI, 48167

Lollipop Day Care Inc 23880 Scotia, Oak Park, MI, 48237

Gingellville Early Childhood 4375 Baldwin Rd, Orion, MI, 48359

Goodison Child Care Center Inc 4461 Collins Rd, Rochester, MI, 48306

First Baptist Child Care Ctr 2601 John R, Troy, MI, 48083

Jcc Child Development Center 6600 West Maple, West Bloomfield, MI, 48322

McDonalds 830 Riverview Dr, Kalamazoo, MI, 49001

McDonalds $3320 \mathrm{~S}$ Westnedge, Kalamazoo, MI, 49008

McDonalds 423 W. 11 Mile/Lafayette, Royal Oak, MI, 48067

McDonalds 22525 Woodward, Ferndale, MI, 48220

McDonalds 808 Rochester Rd., Rochester, MI, 48307

McDonalds 2985 Walton Blvd./Adams, Rochester Hills, MI, 48309

McDonalds $141 \mathrm{~N}$. Telegraph (Oil), Waterford, MI, 48328

McDonalds $925 \mathrm{~S}$. Ortonville Rd., Ortonville, Ml, 48462

McDonalds 1535 S. Main St., Chelsea, MI, 48118

McDonalds 22100 Pontial Trail, South Lyon, MI, 48178

McDonalds 5550 W. Michigan Ave, Ypsilanti, MI, 48197

Eastwood Towne Center US-127 \& Lake Lansing Road, 1500 Lake Lansing Rd., Lansing, Ml 48840

Great Lakes Crossing Shopping Mall 4000 Baldwin Road, Auburn Hills, MI 48326

Briarwood Mall 100 Briarwood Circle, Ann Arbor, Ml

Busch's Valu Land 3219 Broad St, Dexter, MI 48130

Farmer Jack 21800 W 11 Mile Rd, Southfield, MI 48076

Farmer Jack Mkt. 7121 Dixie Hwy, Clarkston, MI 48346

FELPAUSCH FOOD CENTER 120 W PRAIRE ST, VICKSBURG 49097

HARDING'S MARKET 2626 E MAIN, KALAMAZOO 49001

HARDING'S MARKET 5161 W MAIN ST, KALAMAZOO 49009

HARDING'S MARKET 6330 S WESTNEDGE, PORTAGE 49002

HARDING'S MARKET 6430 W MICH BX 154, OSHTEMO 49007

HOLIDAY FOOD CENTER 1203 S MAIN, ROYAL OAK 48067

Kmart 29101 John R Rd, Madison Heights, MI 48071
Day Care

Day Care

Day Care

Day Care

Day Care

Day Care

McDonalds

McDonalds

McDonalds

McDonalds

McDonalds

McDonalds

McDonalds

McDonalds

McDonalds

McDonalds

McDonalds

Grocery/Shopping 1

Grocery/Shopping 1

Grocery/Shopping 1

Grocery/Shopping 1

Grocery/Shopping 1

Grocery/Shopping 1

Grocery/Shopping 1

Grocery/Shopping 1

Grocery/Shopping 1

Grocery/Shopping 1

Grocery/Shopping 1

Grocery/Shopping 1
Day Care

Grocery/Shopping 1 


\begin{tabular}{|c|c|c|c|}
\hline 036 & Kalamazoo & 4620 Stadium Dr, Kalamazoo, Ml 49008 & Grocery/Shopping \\
\hline 037 & Kalamazoo & 6355 S Westnedge Ave, Portage, MI 49002 & Grocery/Shopping \\
\hline 038 & Oakland & 20730 Pontiac Trl, South Lyon, Ml 48178 & Grocery/Shopping \\
\hline 039 & Oakland & 25780 Middlebelt Rd, Farmington, MI 48336 & Grocery/Shopping \\
\hline 040 & Washtenaw & 400 S Maple Rd, Ann Arbor, Ml 48103 & Grocery/Shopping \\
\hline 041 & Washtenaw & 5645 Jackson Rd, Ann Arbor, MI 48103 & Grocery/Shopping \\
\hline 042 & Kalamazoo & 5800 Gull Rd, Kalamazoo, Ml 49048 & Grocery/Shopping \\
\hline 043 & Ingham & Target 4890 Marsh Rd, Okemos, Ml 48864 & Grocery/Shopping \\
\hline 044 & Oakland & WIDE AWAKE MARKET 914 LIVERNOIS, FERNDALE 48220 & Grocery/Shopping \\
\hline 045 & Grand Traverse & Orchard Creek Child Care Center 9731 E Cherry Bend Rd, Traverse City, MI, 49684 & Day Care \\
\hline 046 & Grand Traverse & Central Day Care Center 222 Cass St, Traverse City, MI, 49684 & Day Care \\
\hline 047 & Livingston & Lakeland Montessori School 5520 M-36, Lakeland, MI, 48143 & Day Care \\
\hline 048 & Jackson & Starting Small 3480 Sargent Rd, Jackson, MI, 49201 & Day Care \\
\hline 049 & Jackson & ABC Academy II 3210 Lansing Avenue, Jackson, MI, 49202 & Day Care \\
\hline 050 & Livingston & I X L Learning Center Inc. 7012 E. M-36 Suite A, Hamburg, MI, 48139 & Day Care \\
\hline 051 & Macomb & Richmond Early Learning Center 68560 Stoecker Lane, Richmond, MI, 48062 & Day Care \\
\hline 052 & Macomb & Maynard Education Center 3423 Auburn Rd, Shelby Township, MI, 48317 & Day Care \\
\hline 053 & Macomb & Heritage Carousel Child Care 37400 Dodge Park, Sterling Height, MI, 48312 & Day Care \\
\hline 054 & Macomb & KinderCare Learning Center \#808 1383019 Mile Road, Sterling Heights, MI, 48313 & Day Care \\
\hline 055 & Macomb & $\begin{array}{l}\text { Warren Woods Day Care Hawthorne Complex, } 12900 \text { Frazho Road, Warren, MI, } \\
48089\end{array}$ & Day Care \\
\hline 056 & Bay & McDonalds 2515 S Huron Rd, Kawkawlin, MI, 48631 & McDonalds \\
\hline 057 & Eaton & 5225 N Grand River Ave, Lansing, MI, 48917 & McDonalds \\
\hline 058 & Kent & 414117 Mile Rd, Cedar Springs, MI, 49319 & McDonalds \\
\hline 059 & Kent & 450 W Division, Sparta, MI, 49345 & McDonalds \\
\hline 060 & Kent & 417 Michigan St, Grand Rapids, MI, 49503 & McDonalds \\
\hline 061 & Kent & 3030 Walker Ave, Walker, MI, 49504 & McDonalds \\
\hline 062 & Kent & 531 68th St SW, Grand Rapids, MI, 49508 & McDonalds \\
\hline 063 & Macomb & 41500 Garfield Rd., Clinton Twp, MI, 48038 & McDonalds \\
\hline 064 & Macomb & 25900 Crocker, Mt. Clemens, MI, 48045 & McDonalds \\
\hline 065 & Macomb & 15401 E. 12 Mile/Callahan, Roseville, MI, 48066 & McDonalds \\
\hline 066 & Ottawa & McDonalds 213 N River Rd, Holland, MI, 49424 & McDonalds \\
\hline 067 & Macomb & $\begin{array}{l}\text { Lakeside Mall } 14000 \text { Lakeside Circle M } 59 \text { (Hall Road) at Schoenherr Road, } \\
\text { Sterling Heights, MI }\end{array}$ & Grocery/Shopping \\
\hline 068 & Kent & Rivertown Crossings 3700 RiverTown Parkway, Grandville, MI & Grocery/Shopping \\
\hline 069 & Macomb & Farmer Jack 9 Mile At Kelly, Eastpointe, MI 48021 & Grocery/Shopping \\
\hline 070 & Macomb & Farmer Jack Groesbeck At Cass, Mount Clemens, MI 48043 & Grocery/Shopping \\
\hline 071 & Jackson & FRANKS SHOPRITE $\quad 400$ MICHIGAN AVE, GRASS LAKE 49240 & Grocery/Shopping \\
\hline 072 & Kent & FULTON HEIGHTS FOODS 2420 EASTERN AVE, GRAND RAPIDS 49507 & Grocery/Shopping \\
\hline 073 & Midland & GLENS/MIDLAND 2026 N SAGINAW ST, MIDLAND 49640 & Grocery/Shopping \\
\hline
\end{tabular}




\begin{tabular}{|c|c|c|c|}
\hline 074 & Kent & 4111 N Kent Mall NE, Grand Rapids, MI 49525 & Grocery/Shopping \\
\hline 075 & Bay & 2910 Center Ave, Essexville, Ml 48732 & Grocery/Shopping \\
\hline 076 & Eaton & 6430 W Saginaw Hwy, Lansing, MI 48917 & Grocery/Shopping \\
\hline 077 & Grand Traverse & MAXBAUERS MARKET 407 S UNION, TRAVERSE CITY 49684 & Grocery/Shopping \\
\hline 078 & Jackson & Meijer 2777 Airport Rd, Jackson, MI 49202 & Grocery/Shopping \\
\hline 079 & Eaton & 5125 W Saginaw Hwy, Lansing, Ml 48917 & Grocery/Shopping \\
\hline 080 & Kent & 5500 Clyde Park Ave SW, Wyoming, MI 49509 & Grocery/Shopping \\
\hline 081 & Ottawa & Meijer $\quad 746 \mathrm{E} 16$ th St, Holland, Ml 49423 & Grocery/Shopping \\
\hline 082 & Bay & PINNY FOOD CENTER 704 S MABLE BX 597, PINCONNING 48650 & Grocery/Shopping \\
\hline 083 & Livingston & ROSATI'S MARKETPLACE 130 S. GRAND RD., FOWLERVILLE 48836 & Grocery/Shopping \\
\hline 084 & Macomb & SAVEWAY PLUS FOOD CENTER 20900 GRATIOT, EASTPOINTE 49021 & Grocery/Shopping \\
\hline 085 & Macomb & SHOPPERS MARKET 22800 VAN DYKE, WARREN 48089 & Grocery/Shopping \\
\hline 086 & Macomb & STAHL'S MARKET 39050 HARPER, CLINTON TOWNSHIP, MI. 49228 & Grocery/Shopping \\
\hline 087 & Grand Traverse & $\begin{array}{l}\text { TOM'S FOOD MARKET W BAY SHOPPING CNTR , M-22 \& M-72, TRAVERSE CITY } \\
49684\end{array}$ & \\
\hline 088 & Macomb & 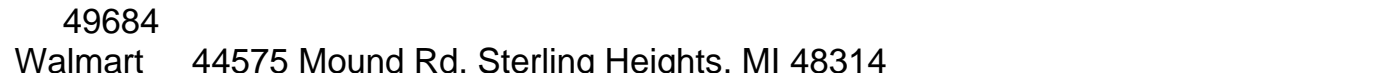 & Grocery/Shopping \\
\hline 089 & Berrien & $\begin{array}{l}\text { Walmart } 44575 \text { Mound Rd, Sterling Heights, MI } 48314 \\
\text { Kids Corner Preschool \& Childcare } 7048 \text { Curtis Drive, Coloma, MI, } 49038\end{array}$ & Day Care \\
\hline 090 & Calhoun & Little Friends Day Care 1305 Olive Street, Battle Creek, MI, 49017 & Day Care \\
\hline 091 & Clinton & Fuerstenau KIDS/Little Panthers 205 Washington, Dewitt, MI, 48820 & Day Care \\
\hline 092 & Genesee & Bethel Child Care Center 6029 Lapeer Rd, Burton, MI, 48509 & Day Care \\
\hline 093 & Isabella & Childrens Learning Center - Bamber 1651 S Bamber Rd, Mt Pleasant, MI, 48858 & Day Care \\
\hline 094 & Lenawee & Y Young Scholars Nursery 638 West Maumee St, Adrian, MI, 49221 & Day Care \\
\hline 095 & Lenawee & Tee Pee Learning Center 3651 Russell Rd, Tecumseh, MI, 49286 & Day Care \\
\hline 096 & Monroe & Tender Hands Child Care Center 1030 East Second St., Monroe, MI, 48161 & Day Care \\
\hline 097 & Muskegon & Gustafson Early Childhood Center 2820 MacArthur Road, Muskegon, MI, 49442 & Day Care \\
\hline 098 & Saginaw & Kids Korner 2030 N Carolina St, Saginaw, MI, 48605 & Day Care \\
\hline 099 & Shiawassee & Little Conquerors $\quad$ P. O. Box 250, 901 E Grand River, Laingsburg, MI, 48848 & Day Care \\
\hline 100 & Genesee & McDonalds 213 N State St, Otisville, MI, 48463 & McDonalds \\
\hline 101 & Genesee & 3212 Clio Rd, Flint, MI, 48504 & McDonalds \\
\hline 102 & Genesee & G-3391 S Saginaw St, Burton, MI, 48529 & McDonalds \\
\hline 103 & Ionia & 2784 S State St, Ionia, MI, 48846 & McDonalds \\
\hline 104 & Ionia & 1432 E Grand River, Portland, MI, 48875 & McDonalds \\
\hline 105 & Lapeer & 486 S. Main St., Lapeer, MI, 48446 & McDonalds \\
\hline 106 & Lenawee & 503 S Meridian St, Hudson, MI, 49247 & McDonalds \\
\hline 107 & Muskegon & 3586 E Apple Ave, Muskegon, MI, 49442 & McDonalds \\
\hline 108 & Saginaw & 2745 Bay Rd, Saginaw, MI, 48603 & McDonalds \\
\hline 109 & Saginaw & 6331 Dixie Hwy, Bridgeport, MI, 48722 & McDonalds \\
\hline 110 & St. Joseph & McDonalds 1024 Michigan Ave, Three Rivers, MI, 49093 & McDonalds \\
\hline 111 & Muskegon & Lakeshore Market Place 5241 Harvey, Muskegon, MI & Grocery/Shopping \\
\hline 112 & Marquette & Westwood Mall 3020 US 41 West, Marquette, MI & Grocery/Shopping \\
\hline
\end{tabular}


Lenawee

Lenawee

Genesee

St. Joseph

Genesee

Genesee

Genesee

Saginaw

Lenawee

Saginaw

Muskegon

Saginaw

Isabella

Berrien

Lenawee

Van Buren

St. Joseph

Van Buren

Shiawassee

Monroe

Wayne

Wayne

Wayne

Wayne

Wayne

Wayne

Wayne

Wayne

Wayne

Wayne

Wayne

Wayne

Wayne

Wayne

Wayne

Wayne

Wayne

Wayne

Wayne

Wayne
BORCHARDT BROTHERS MARKET 628 W ADRIAN ST, BLISSFIELD 49228

Busch's Valu Land 1450 W Chicago Blvd, Tecumseh, MI 49286

Kmart 1145 N Belsay Rd, Burton, Ml 48509

Kmart 1320 Broadway, Three Rivers, MI 49093

Kmart 6105 N Saginaw Rd, Mount Morris, MI 48458

Kmart G3083 Miller Rd, Flint, MI 48507

Kroger 2629 W Pierson Rd, Flint, MI 48504

Kroger 3430 State St, Saginaw, MI 48602

Meijer 217 E US Highway 223, Adrian, MI 49221

Meijer 8400 Gratiot Rd, Saginaw, MI 48609

Target $1740 \mathrm{E}$ Sherman Blvd, Muskegon, MI 49444

Target 2772 Tittabawassee Rd, Saginaw, MI 48604

Target 4097 E Blue Grass Rd, Mount Pleasant, MI 48858

Target 960 Fairplain Dr,, Benton Harbor, MI 49022

THE PHARM/ADRIAN 124 E FRONT STREET, ADRIAN 49221

VILLAGE MARKET 407 N STATE ST M40, GOBLES 49055

$\begin{array}{lrll}\text { VILLAGE MARKET } & 407 \text { N STATE ST M40, GOBLES } 49055 & \text { Grocery/Shopping } 3 \\ \text { VILLAGE MARKET FOOD CENTER } & 300 \text { ENTERPRISE DR, THREE RIVERS } 49093 \text { Grocery/Shopping } 3\end{array}$

WAGONER'S 24064 MCGILLEN, MATTAWAN 49071

Walmart 1621 E M 21, Owosso, MI 48867

Walmart 2155 N Telegraph Rd, Monroe, Ml 48162

J B Day Nursery Inc 17505 Russell, Allen Park, MI, 48101

Peter Rabbit Day Care Ctr Inc 5901 Cadieux, Detroit, MI, 48224

St Johns Presby Day Care Cen 1961 E Lafayette, Detroit, MI, 48207

Kreative Child Care Center Inc 9226 Kercheval, Detroit, MI, 48214

Christ Liberty Ministry Child Care 14305 E. Seven Mile, Detroit, MI, 48205

Sugar N Spice 16555 Wyoming, Detroit, MI, 48221

Memorial Nursery Inc 16 Lake Shore Rd, Grosse Pte Fms, MI, 48236

Rainbow Child Development Center 19251 Mack Ave, Grosse Pte Wds, MI, 48236

L.G. and Daughters Child Care 17461 Allen Road, Melvindale, MI, 48122

Northville First Care 777 W Eight Mile Rd, Northville, MI, 48167

Nanny's Eureka Heights 25125 Eureka, Taylor, MI, 48180

McDonalds 15405 Southfield Rd., Allen Park, MI, 48101

McDonalds $4145 \mathrm{~S}$. Telegraph, Dearborn Hgts., MI, 48125

McDonalds 27255 Telegraph Rd., Flat Rock, MI, 48134

McDonalds 1469 Fort St, Lincoln Park, MI, 48146

McDonalds 39700 Five Mile/Haggerty, Plymouth, MI, 48170

McDonalds 23000 Eureka Rd., Taylor, MI, 48180

McDonalds 1581 Van Horn, Trenton, MI, 48183

McDonalds 38418 Ford Road/Hix, Westland, MI, 48185

McDonalds 3975 Conner, Detroit, MI, 48215
Grocery/Shopping 3

Grocery/Shopping 3

Grocery/Shopping 3

Grocery/Shopping 3

Grocery/Shopping 3

Grocery/Shopping 3

Grocery/Shopping 3

Grocery/Shopping 3

Grocery/Shopping 3

Grocery/Shopping 3

Grocery/Shopping 3

Grocery/Shopping 3

Grocery/Shopping 3

Grocery/Shopping 3

Grocery/Shopping 3

Grocery/Shopping 3

Grocery/Shopping 3

Grocery/Shopping 3

Day Care

Day Care

Day Care

Day Care

Day Care

Day Care

Day Care

Day Care

Day Care

Day Care

Day Care

McDonalds

McDonalds

McDonalds

McDonalds

McDonalds

McDonalds

McDonalds

McDonalds

McDonalds 


$\begin{array}{ll}153 & \text { Wayne } \\ 154 & \text { Wayne } \\ 155 & \text { Wayne } \\ 156 & \text { Wayne } \\ 157 & \text { Wayne } \\ 158 & \text { Wayne } \\ 159 & \text { Wayne } \\ 160 & \text { Wayne } \\ 161 & \text { Wayne } \\ 162 & \text { Wayne } \\ 163 & \text { Wayne } \\ 164 & \text { Wayne } \\ 165 & \text { Wayne } \\ 166 & \text { Wayne } \\ 167 & \text { Wayne } \\ 168 & \text { Wayne } \\ 169 & \text { Wayne } \\ 170 & \text { Wayne } \\ 171 & \text { Wayne } \\ 172 & \text { Wayne } \\ 173 & \text { Wayne } \\ 174 & \text { Wayne } \\ 175 & \text { Wayne } \\ 176 & \text { Wayne }\end{array}$

McDonalds 22021 W. 8 Mile Rd., Detroit, MI, 48219

McDonalds 17800 E. 8 Mile/Kelly, Harper Woods, MI, 48225

Laurel Park Place 37700 West Six Mile Road, Livonia, MI

Sears Lincoln Park Southfield Road \& Dix Highway, Lincoln Park, MI

Wonderland Mall 29859 Plymouth Road, Livonia, MI

Farmer Jack W Fort At Emmons, Lincoln Park, MI 48146

Farmer Jack Market 200 S Merriman Rd, Westland, MI, 48186

Farmer Jack Mkt. 19150 W 7 Mile Rd, Detroit, MI 48219

Farmer Jack Mkt. 296597 Mile Rd, Livonia, Ml 48152

Farmer Jack Mkt. 7350 N Middlebelt Rd, Westland, MI 48185

FARMER'S FOOD CENTER, 2411 CENTRAL AVE, DETROIT MI 48209

FOOD PRIDE SUPERMARKET, 500 EAST WARREN, DETROIT MI 48201

HARBORTOWN FOODS, 3472 EAST JEFFERSON, DETROIT MI 48207

HOLIDAY MARKET 520 S. LILLEY ROAD, CANTON 48188

K \& G FOOD MART, 2662 W DAVISON, DETROIT MI 48238

Kmart 2095 Rawsonville Rd, Belleville, MI 48111

Kroger 1905 N Canton Center Rd, Canton, MI 48187

Kroger 23303 Michigan Ave, Dearborn, Ml 48124

Kroger 45540 Michigan Ave, Canton, MI 48188

NEW MERCHANT FOOD CENTER, 2819 E SEVEN MILE, DETROIT MI 48234

SAK ' N SAVE 1647 MERRIMAN, WESTLAND 48185

Target 20100 Haggerty Rd, Livonia, MI 48152

Target 30007 Plymouth Rd, Livonia, MI 48150

VALUE SAVE FOOD CENTER 14470 LIVERNIOS, DETROIT 48238
McDonalds

McDonalds

Grocery/Shopping 4

Grocery/Shopping 4

Grocery/Shopping 4

Grocery/Shopping 4

Grocery/Shopping 4

Grocery/Shopping 4

Grocery/Shopping 4

Grocery/Shopping 4

Grocery/Shopping 4

Grocery/Shopping 4

Grocery/Shopping 4

Grocery/Shopping 4

Grocery/Shopping 4

Grocery/Shopping 4

Grocery/Shopping 4

Grocery/Shopping 4

Grocery/Shopping 4

Grocery/Shopping 4

Grocery/Shopping 4

Grocery/Shopping 4

Grocery/Shopping 4

Grocery/Shopping 4 